\title{
WOBBLING BACK TO THE FIRE: ECONOMIC EFFICIENCY AND THE CREATION OF A RETAIL MARKET FOR SET-TOP BOXES
}

\author{
T. Randolph Beard, PhD, ${ }^{*}$ George S. Ford, $\mathrm{PhD},{ }^{\dagger}$ Lawrence J. \\ Spiwak, Esq., ${ }^{\ddagger}$ Michael Stern, $\mathrm{PhD}^{\bullet}$
}

\section{INTRODUCTION}

As part of the sweeping Telecommunications Act of 1996, Congress directed the Federal Communications Commission ("FCC") to adopt regulations "to assure the commercial availability ... of converter boxes, interactive communications equipment, and other equipment used by consumers to access multichannel video programming ... from manufacturers, retailers, and other vendors ...."' Yet, despite considerable effort and at least one billion dollars spent to implement the agency's "CableCard" regime, ${ }^{2}$ the FCC repeatedly

* Senior Fellow, Phoenix Center for Advanced Legal \& Economic Public Policy Studies; Professor of Economics, Auburn University.

† Chief Economist, Phoenix Center for Advanced Legal \& Economic Public Policy Studies.

¥ President, Phoenix Center for Advanced Legal \& Economic Public Policy Studies. The views expressed in this paper are the authors' alone and do not represent the views of the Phoenix Center or its staff.

- Senior Fellow, Phoenix Center for Advanced Legal \& Economic Public Policy Studies; Associate Professor of Economics, Auburn University.

1 Telecommunications Act of 1996, Pub. L. No. 104-104, §304, 110 Stat. 56, 125-126 (1996) (codified at 47 U.S.C. § 549(a) (2006)).

2 See discussion infra Part III.A; see, e.g., In re Video Device Competition; Implementation of Section 304 of the Telecommunications Act of 1996; Commercial Availability of Navigation Devices; Compatibility Between Cable Systems and Consumer Electronics Equipment, Notice of Inquiry, 25 F.C.C.R. 4275, 4301 (Apr. 21, 2010) (statement of Comm'r Baker) ("As we consider a long-term solution, I hope that we recall valuable lessons from the CableCARD regime. First, our technological mandates come with significant 
concedes that its "efforts [to implement Section 629] to date have not led to a robustly competitive retail market for navigation devices that connect to subscription video services." Indeed, only about one percent of navigation devices are purchased at retail. ${ }^{4}$ This profound lack of interest in such devices, which are available at big-box electronic stores, is a significant indictment of the agency's implementation of Section 629. If the acquisition of set-top boxes in a commercial market had even moderate consumer interest, then it seems reasonable to assume that the share of the market for such devices would be higher than one percent. ${ }^{5}$

Frustrated by its billion-dollar policy dud, the FCC has recently expressed a renewed interest in Section 629. ${ }^{6}$ In its National Broadband Plan, ${ }^{7}$ and then in

costs. By one estimate, the cost of CableCARD compliance for the cable industry alone costs passed on to cable consumers - has totaled nearly one billion dollars. Second, we should be careful not to mandate particular technological solutions that would freeze into place the current state of technology.") [hereinafter AllVid NOI] (citation omitted).

3 Id. I 10; see also In re Implementation of Section 304 of the Telecommunications Act of 1996: Commercial Availability of Navigation Devices; Compatibility Between Cable Systems and Consumer Electronics Equipment; Oceanic Time Warner Cable, a subsidiary of Time Warner Cable, Inc.; Oceanic Time Warner Cable, a division of Time Warner Cable, Inc., Oceanic Kauai Cable System; Oceanic Time Warner Cable, a division of Time Warner Cable, Inc., Oceanic Oahu Central Cable System; Cox Communications Inc., Fairfax County, Virginia Cable System; Cable One, Inc.'s Request for Waiver of Section 76.1204(a)(1) of the Commission's Rules, Third Report and Order and Order on Reconsideration, 25 F.C.C.R. 14,657, 1/ 4 (Oct. 14, 2010) ("Unfortunately, the Commission's efforts to date have not developed a vigorous competitive market for retail navigation devices that connect to subscription video services.") [hereinafter Commercial Availability III]; FCC, CONNECTING America: THE NATIONAL BROADBAND PLAN 50 (2010), available at http://commcns.org/sCCj9m. ("Despite Congressional and FCC intentions, CableCARDs have failed to stimulate a competitive retail market for set-top boxes.") [hereinafter NATIONAL BROADBAND PLAN].

4 Commercial Availability III, supra note 3, I 4.

5 Even when consumers have the option to buy rather than lease equipment (e.g., the cable broadband modem), the demand is low. See, e.g., Comment Sought on Video Device Innovation, NBP Public Notice \#27, Letter from National Cable \& Telecomm. Ass'n, GN Docket Nos. 09-47, 09-51, 09-137, CS Docket No. 97-80 (Dec. 4, 2009) (accessible via FCC Electronic Comment Filing System) [hereinafter NBP Public Notice].

6 Indeed, in the National Broadband Plan, the Commission expressed its exasperation about the failed CableCARD experiment, lamenting that a "national or global market with relatively low costs of entry, like that for many consumer electronics markets, should support more than two competitors [i.e., manufacturers of set-top boxes] over time." NATIONAL Broadband Plan, supra note 3, at 50. According to the Commission, this is because "[r]etail set-top boxes have been competing on an uneven playing field[]" that has "prompted some companies not to enter the market at all." Id. at 51,67 n.115 (citing a news article reporting on Steve Jobs' reluctance to produce Apple TV as a set-top box with access to traditional TV content through MVPDs).

7 Id. at 36. ("The FCC should initiate a proceeding to ensure that all multichannel video programming distributors (MVPDs) install a gateway device or equivalent functionality in all new subscriber homes and in all homes requiring replacement set-top boxes, starting on or before Dec. 31, 2012."). 
a subsequent Notice of Inquiry, ${ }^{8}$ the FCC contemplates a "do-over" for Section 629 , hoping that another hard-line regulatory approach will succeed where the CableCard paradigm has failed. The Commission's new all video ("AllVid") proposal envisions a regulation whereby the $\mathrm{FCC}$ would require multi-channel video programming distributors ("MVPDs") "to provide a small, low-cost adapter that would connect to proprietary MVPD networks and would provide a common interface for connection to televisions, DVRs, and other smart video devices ...." According to the Commission, while this adapter "would perform the conditional access functions as well as tuning, reception, and upstream communication as directed by the smart video device"10 (e.g., an "AllVid Compatible" DVR, television, or home theater personal computer "), the "adapter and the smart video device would communicate with each other using a standard interface, but each adapter would be system-specific to a particular MVPD in order to communicate with its network."12

The AllVid approach should sound familiar. Conceptually, the scheme closely follows the CableCard idea in that AllVid is simply a proposal to separate conditional access from other features of the set-top box in the hopes of creating a retail market for the latter. There are, however, a few notable differences between AllVid and the CableCard. First, the FCC seeks to expand regulation coverage to include direct broadcast satellite ("DBS") providers, which are presently excluded from the CableCard regulatory mandates. ${ }^{13}$ Consequently, the scope of the AllVid regulation is much more expansive and, therefore, will likely be more difficult to design, implement, and administer given the business models of the affected parties and the profound differences in their delivery technologies. ${ }^{14}$ Moreover, by applying Section 629 to the DBS

8 AllVid NOI, supra note 2, I 10 ("Although following adoption of the CableCARD rules some television manufacturers sold unidirectional digital cable-ready products ('UDCPs'), most manufactures have abandoned the technology.").

9 Id. $ๆ 16$.

$10 I d$.

11 Id. at app. AllVid Concept Illustrations, 4293.

12 Id. 916.

13 In re Implementation of Section 304 of the Telecommunications Act of 1996: Commercial Availability of Navigation Devices, Report and Order, 13 F.C.C.R. 14,775, 7 64-65 (June 11, 1998) ("[W]e do not think that requiring DBS ["direct broadcast satellite"] service providers to separate security elements will serve the goal of enhanced competition in either the service or equipment markets.") [hereinafter Commercial Availability I]

14 AllVid NOI, supra note 2, 12 ("[M] ost consumer electronics manufacturers acknowledge that an attempt to establish standards for navigation devices that would work with each of the different delivery technologies without some intermediation would be impractical and prohibitively expensive."). Recently, the FCC used its Section 629 authority to expressly regulate both the price of equipment and video service. Commercial Availability $I I I$, supra note 3, I 19 ("Accordingly, we also adopt a rule that requires cable operators to reduce the price of packages that include set-top box rentals by the cost of a set-top box rental for customers who use retail devices, and prohibits cable operators from assessing 
industry, the FCC would effectively impose new price regulation of equipment on satellite providers, thus widening the scope of price regulation in the communications industry. ${ }^{15}$ Finally, the Commission seeks not merely to make settop boxes for MVPDs commercially available as mandated by the statute, but intends for AllVid-compatible devices to accommodate the services of nonMVPD sources, such as over-the-top video services. ${ }^{16}$

As is too often the case with bold Commission policy initiatives, the agency's aggressive attempt to implement Section 629 has proceeded entirely without any formal economic analysis of the nature of the service-equipment relationship in the MVPD market. In this paper, we attempt to remedy that shortcoming. Our findings are potentially significant in several respects.

First, in contrast to the common view that the self-supply model of set-top boxes is anticompetitive and anti-consumer, our theoretical analysis reveals that the set-top box conveys no market power to the MVPD, even if we assume that the provider of multichannel video services is a monopoly. Set-top boxes are necessary appendages (i.e., complements) to subscription video services and, as such, the provider can obtain all profits from the service itself. ${ }^{17}$

Second, our analysis indicates that the MVPD has no anticompetitive preference for self-supply. If the equipment can be produced more efficiently and sold at a lower price in a competitive retail market, then the provider will embrace such a market to the benefit of both provider and consumer. However, if the equipment can be sold at a lower price through self-supply, then the providers will prefer that option, which will also benefit both provider and consumer.

service fees on consumer-owned devices that are not imposed on leased devices. These price reductions must reflect the portion of the package price that is reasonably allocable to the device lease fee.").

15 Telecommunications Act of $1996 \S 304,47$ U.S.C. $\S 549$ (a) (2006) (" $[R]$ egulations shall not prohibit any [MVPD] from also offering converter boxes ... to consumers, if the system operator's charges to consumers for such devices and equipment are separately stated and not subsidized by charges for any such service."). Thus, under Section 629 , firms do not have complete freedom to set prices for set-top equipment. $I d$.

16 AllVid NOI, supra note 2, 17 ("This approach would provide the necessary flexibility for consumer electronics manufacturers to develop new technologies, including combining MVPD content with over-the-top video services (such as videos offered from, for example, Amazon, Hulu, iTunes, or NetFlix), manipulating the channel guide, providing more advanced parental controls, providing new user interfaces, and integrating with mobile devices.").

17 See, e.g., In re Video Device Competition: Implementation of Section 304 of the Telecommunications Act of 1996; Commercial Availability of Navigation Devices; Compatibility Between Cable Systems and Consumer Electronics Equipment, Reply Comments of the National Cable \& Telecommunications Association, MB Docket No. 10-91, CS Docket No. 97-80, PP Docket No. 00-67, at 2 (Aug. 12, 2010) (available via FCC Electronic Comment Filing System) ("[S]et-top boxes are an enabler of our core service, which is video, not equipment."). 
Third, this paper demonstrates that a government-directed commercial market for set-top boxes is unlikely to provide substantial gains in terms of lower costs, lower prices, or increased innovation. If the set-top box can be manufactured at a lower cost and sold at a lower price, then the MVPD will embrace the cost reduction, profits will rise, and consumers will benefit. Also, if innovation increases the value of set-top boxes to consumers, the MVPD is incentivized to implement that innovation. As a result, profits will be higher and consumers will be better off. Because the incentives to reduce prices and increase innovation remain intact, the prospects for a forced commercial market are slim. That is, where a commercial market produces lower costs and spurs innovation, the FCC will not need to mandate such a market because industry would welcome it.

When placed within an economic framework, the FCC's heavy-handed approach to Section 629 is largely misguided. It may truthfully be characterized as "[t]he burnt Fool's bandaged finger go[ing] wabbling back to the fire."18 History has shown that MVPDs prefer an efficient outcome, and since markets detest inefficiency, a heavy-handed regulatory approach to Section 629 is doomed to fail. Therefore, our simple economic analysis of set-top boxes-the first of its kind on this issue-encourages the FCC to substantially reorient its thinking on Section 629. The economics of the service-equipment relationship in multichannel video prescribes a light-touch approach for set-top boxes, one much different from the agency's oppressive AllVid (and CableCard) proposal.

So what is the FCC to do? If the existing market mechanism of self-supply for set-top boxes is, in fact, inefficient, then it is doubtful that either the Commission's recent modifications to the CableCard regime ${ }^{19}$ or its new AllVid proposal will produce a different result than that observed thus far. ${ }^{20}$ Competition is evolving in video delivery without the technology-specific mandates of Section 629, and an efficient commercial market for set-top boxes will emerge without similar regulatory interference. An inefficient commercial market will not evolve naturally, but government action could create and sustain it. For the Commission's efforts to implement Section 629 to succeed, not only must policy change, but the fundamental economics of the service-equipment relationship in the multichannel video market must also change. This Article argues that, until the underlying economic reality changes, perhaps due to some technological innovation, the FCC's anticipated aggressive approach to Section 629 will likely keep the agency in "the Valley of Unattained Goals."21 Given

18 Rudyard Kipling, The Gods of Copybook Maxims, HARPER'S MONTHLY MAG., Jan. 1920 , at 146.

19 Commercial Availability III, supra note 3, | 13.

20 See, e.g., AllVid NOI, supra note 2, at 4301 (statement of Comm'r Baker).

21 Commercial Availability III, supra note 3, at 14,711 (statement of Comm'r McDowell). 
these economic realities, perhaps it is time for the Commission to develop a way to satisfy the requirements necessary to invoke the sunset provision of Section $629 .^{22}$

This Article proceeds in Part II with a brief summary of Section 629. Part III outlines the Commission's prior attempts to implement Section 629, discussing both the CableCard paradigm and the newly proposed AllVid regime. Part III then examines the arguments as to why the CableCard experiment failed, and why the agency believes a new AllVid regime is required. Next, Parts IV and $\mathrm{V}$ present an economic analysis of the problem and explain why past approaches to implement Section 629 were doomed to fail. In turn, Part VI sets forth fact-based legal and economic arguments to satisfy the sunset requirements of Section 629 , should the Commission elect to go down that path. Finally, Section VII outlines conclusions and policy recommendations.

\section{SECTION 629 OF THE TELECOMMUNICATIONS ACT}

Section 629 was added to the Communications Act by way of the Telecommunications Act of $1996 .{ }^{23}$ Congress, seeing that it was possible to have retail competition for telephone customer premises equipment, enacted Section 629 with similar aspirations for set-top boxes. ${ }^{24}$ Specifically, Section 629 instructs the FCC to:

[A]dopt regulations to assure the commercial availability, to consumers of . . equipment used ... to access multichannel video programming and other services offered over multichannel video programming systems, from manufacturers, retailers, and other vendors not affiliated with any multichannel video programming distributor. ${ }^{25}$

A plain reading of the statute implies that consumers should be able to purchase this equipment from sources other than the service provider. ${ }^{26}$ Generally, MVPDs are not vertically integrated with manufacturers of set-top boxes, but they can purchase boxes from companies such as Motorola, Cisco, Samsung, Panasonic, and Pace. ${ }^{27}$ Nonetheless, these boxes are typically designed to handle the particular needs of individual MVPDs and, consequently, cannot be shuttled across different MVPD platforms. ${ }^{28}$

See 47 U.S.C. § 549(e).

2347 U.S.C. $\$ 549$.

24 Commercial Availability I, supra note 13, 111 ("The competitive market for consumer equipment in the telephone context provides the model of a market we have sought to emulate in this proceeding."). See also AllVid NOI, supra note 2, I| 4.

$25 \quad 47$ U.S.C. \& 549(a).

26 Commercial Availability I, supra note 13, I 1 .

27 Id. I 99; Ralitza A. Grigorova-Minchev \& Thomas W. Hazlett, Policy-Induced Competition: The Case of Cable TV Set-Top Boxes, 12 MiNN. J.L. SCI. \& TECH. 279, 297-98 (2011).

28 AllVid NOI, supra note 2, ๆ 15. 
Other restrictions in the statute are also helpful in determining Congress' intent with respect to the implementation of Section 629. First, in adopting such regulations, the FCC shall "consult[] with appropriate industry standard-setting organizations."29 Second, the FCC cannot prohibit MVPDs from also offering equipment to their subscribers "if the system operator's charges to consumers for such devices and equipment are separately stated and not subsidized by charges for" multichannel video programming and other services. ${ }^{30}$ Thus, by statute, MVPDs may be active participants in a retail set-top box market, though the prices charged for such equipment are subject to some regulatory limitations. ${ }^{31}$ The language of the Act suggests a minimum, cost-based price requirement. This interpretation will be addressed in further detail below.

The statute also authorizes the FCC to grant waivers under certain conditions, ${ }^{32}$ while providing some other limitations. ${ }^{33}$ Sunset provisions permit the FCC to set aside entirely the equipment mandates if the following three conditions are met: (1) the MVPD market is "fully competitive;" (2) there is a "fully competitive" market for "converter boxes[] and interactive communications equipment;" and (3) the absence of the regulation will serve the public interest and encourage competition. ${ }^{34}$ In the past, the agency has granted numerous Section 629 waivers $^{35}$ and found justification in the marketplace to exclude DBS distributors from its implementation mandates. ${ }^{36}$

\section{IMPLEMENTATION EFFORTS TO DATE}

As the history of how the FCC initially sought to implement Section 629 is tortured and complex, this Part will provide only a brief history. Notably, the

2947 U.S.C. $\$ 549(\mathrm{a})$.

30 Id.

31 Equipment may also be subject to regulation pursuant to Section 623 of the Act. See 47 U.S.C. $\S 543$.

3247 U.S.C. \& 549(c).

33 See, e.g., 47 U.S.C. $\$ 549(\mathrm{~d})(1)$.

$34 \quad 47$ U.S.C. \& 549(e).

35 See, e.g., In re Cablevision Systems Corporation's Request For Waiver of Section 76.1204(a)(1) of the Commission's Rules; Implementation of Section 304 of the Telecommunications Act of 1996; Commercial Availability of Navigation Devices, Memorandum Opinion and Order, 22 F.C.C.R. 220, १ๆ 22-23 (Jan. 10, 2007) [hereinafter January Waiver Requests]; In re Consolidated Requests For Waiver of Section 76.1204(a)(1) of the Commission's Rules; Implementation of Section 304 of the Telecommunications Act of 1996; Commercial Availability of Navigation Devices, Memorandum Opinion and Order, 22 F.C.C.R. 11780, ๆ 63 (June 29, 2007) [hereinafter June Waiver Requests]; In re Guam Cablevision, LLC; Request for Waiver of Section 76.1204(a)(1) of the Commission's Rules; Implementation of Section 304 of the Telecommunications Act of 1996; Commercial Availability of Navigation Devices, Memorandum Opinion and Order, 22 F.C.C.R. 11747, I 17 (June 29, 2007) [hereinafter Guam Cablevision Memorandum].

36 Commercial Availability I, supra note 13, I 64. 
agency's CableCARD proposal has withstood numerous statutory challenges. ${ }^{37}$

\section{A. The Failed CableCARD Experiment}

When the FCC first sought to implement Section 629, it had to reconcile the statutory goals of assuring the "commercial availability" of navigation devices with that of avoiding any major risks to content security. ${ }^{38}$ The FCC reasoned that if it could somehow split a typical set-top box into two separate components-i.e., the operational and functional components on one hand and the access control features on the other-it would be possible to have the first part available through retail outlets and the second part, containing the more sensitive access control apparatus, available only from the service provider (i.e., the cable operator). ${ }^{39}$ The FCC, noting the danger of “"detailed government standard setting,' left it to the cable industry and its national standard-setting organizations to develop the appropriate interfaces. ${ }^{" 40}$ This interface eventually became the "CableCARD," which is a security device that, when inserted into either the television or set-top box, allows the consumer to view otherwise encrypted video. ${ }^{41}$

But the FCC went one step beyond simply instructing the industry to develop the CableCARD when it imposed an "integration ban," which required cable operators to cease the integration of the security function into set-top boxes leased to consumers. ${ }^{42}$ This ban effectively required the cable operators to use the CableCARD in all of their leased equipment. ${ }^{43}$ While the cable in-

37 See generally Comcast Corp. v. FCC, 526 F.3d 763, 769 (D.C. Cir. 2008) (holding that the FCC's denial of a waiver was not inconsistent with earlier waivers because "the allegedly inconsistent [earlier] waivers were all granted by the FCC's Media Bureau and were not appealed to the Commission."); Charter Commc'ns, Inc. v. FCC, 460 F.3d 31, 45 (D.C. Cir. 2006) (rejecting the cable industry's various challenges to the FCC's decision to retain the integration ban); Gen. Instrument Corp. v. FCC, 213 F.3d 724, 730 (D.C. Cir. 2000) (overcoming the National Cable Television Association's ("NCTA") argument that the integration ban is "squarely foreclosed" by the language of Section 629).

38 In re Implementation of Section 304 of the Telecommunications Act of 1996; Commercial Availability of Navigation Devices, Notice of Proposed Rulemaking, 12 F.C.C.R. 5639, 11 (Feb. 11, 1997) [hereinafter Commercial Availability NPRM]; 47 U.S.C. § 549(a)(b) ("The [FCC] shall not prescribe regulations ... which would jeopardize security of multichannel video programming and other services."); see also Gen. Instrument Corp., 213 F.3d at 728-29 (discussing the Congressional mandate directing the FCC to balance commercial availability with security).

39 Commercial Availability NPRM, supra note $38, \uparrow 34$.

40 Commercial Availability I, supra note 13, ๆ 75; see also Gen. Instrument Corp., 213 F.3d at 728 .

41 AllVid NOI, supra note 2, ๆ 7; see also Gen. Instrument Corp., 213 F.3d at 728 (discussing the history leading up to the establishment of the CableCARD).

42 AllVid NOI, supra note 2, \7; Commercial Availability I, supra note 13, \69.

43 AllVid NOI, supra note $2, \mathbb{\$} 7$. 
dustry fought the integration ban on multiple grounds in court, the FCC prevailed each time. ${ }^{44}$

Although space constraints prevent a detailed exegesis of every legal argument raised in these cases, of particular interest (and germane to the analysis presented here) is the FCC's economic rationale supporting the integration ban. Specifically, the Commission argued that, although the integration ban may impose short-term costs (i.e., higher prices for non-integrated set-top boxes), long-term benefits "likely to flow from a more competitive and open supply market" would outweigh them. ${ }^{45}$ Such benefits include the " "potential savings to consumers from greater choice among navigation devices' . . . the spurring of technological innovations," and the equally amorphous argument that "Congress regarded the commercial availability of navigation devices from independent sources as a benefit in and of itself." ${ }^{\prime 46}$ Rather than test the veracity of the FCC's cost-benefit analysis, however, the D.C. Circuit has repeatedly deferred to the agency's expertise. ${ }^{47}$

Yet, by the FCC's own admission, the hard truth is that the CableCARD experiment achieved neither the Commission's original goal of developing a "competitive market for retail navigation devices," nor Congress' intent of Section $629 .{ }^{48}$ According to the FCC, most cable subscribers continue to use

44 Comcast Corp. v. FCC, 526 F.3d 763, 770 (D.C. Cir. 2008) ("we reject Comcast's argument that the Commission's denial of its waiver request was discriminatory or inconsistent with prior FCC policies."); Charter Comme'ns, Inc. v. FCC, 460 F.3d 31, 41 (D.C. Cir. 2006) (holding that the Commission reasonably concluded that "[i]f cable operators "must take steps to support their own compliant equipment, it seems far more likely that they will continue to support and take into account the need to support services that will work with independently supplied and purchased equipment.") (citation omitted); Gen. Instrument Corp., 213 F.3d at 730 (accepting as reasonable the Commission's construction of the term "converter boxes" as not including "integrated converter boxes," thereby rejecting NCTA's argument that the statute precluded the integration).

45 In re Implementation of Section 304 of the Telecommunications Act of 1996; Commercial Availability of Navigation Devices, Second Report and Order, 20 F.C.C.R., If 29 (Mar. 17, 2005) [hereinafter Commercial Availability II].

46 Charter Commc'ns, Inc., 460 F.3d at 42 (citations omitted) (quoting Commercial Availability II, supra note 45, ( 29).

47 See, e.g., Comcast Corp., 526 F.3d at 767; Charter Commc'ns, Inc., 460 F.3d at 42.

Comcast's argument in support of a waiver under [S]ection 629(c) primarily turns on cost concerns - the company argues that if non-integrated digital [converter] boxes become more expensive, then fewer customers will migrate to digital cable. But from the start, the FCC has conceded that the integration ban may impose short-term costs on cable companies and consumers. It reasoned, however, that those costs "should be counterbalanced to a significant extent by the benefits likely to flow from a more competitive and open supply market," such as lower prices, more choices, and the spurring of technological innovation. We affirmed that determination ... and we may not revisit that conclusion here even if we wished to-which we do not.

Comcast Corp., 526 F.3d at 767 (citations omitted).

48 Commercial Availability III, supra note 3, I 4; S. REP. No. 104-230, at 1, 181 (1996) (Conf. Rep.). 
the traditional set-top boxes leased from their cable operator; only one percent of the total navigation devices that are deployed are purchased at retail. ${ }^{49}$ Thus, as the FCC concedes, this "evidence indicates that many retail device manufacturers abandoned CableCARD before any substantial benefits of the integration ban could be realized." ${ }^{50}$ In other words, the FCC's predicted gains in terms of prices and innovation from the CableCARD regime never arrived. In addition to the unrealized gains, FCC Commissioner Meredith Baker recognized that the costs of CableCARD compliance are estimated to be one billion dollars. ${ }^{51}$ The cost-benefit outcome of the CableCARD is decidedly, and admittedly, unfavorable.

\section{B. So Why Did CableCARD Fail? The Commission's Responses}

As noted above, most observers - including the FCC - consider the CableCARD regime to be a failure. Undeterred, however, the Commission not only recently made tweaks to its existing CableCARD regime, ${ }^{52}$ but it also wants to move on to a successor regime, "AllVid." 53 In the following three sections, we explore the FCC's explanations for why CableCARD failed and, equally as important, what steps the agency believes will be necessary to remedy the problem. In Section IV, we provide an economic explanation for the failure of CableCARD.

\section{The Third Report}

Concurrent with its introduction of the proposed AllVid approach, the Commission recently sought to modify its failed CableCARD regime. ${ }^{54}$ While the Commission stated that it was "sympathetic" to concerns that it was seeking another bite at the CableCARD apple, while simultaneously proposing the AllVid regime, the agency believed it necessary to proceed on both tracks because "CableCARD is a realized technology" and "consumer electronics manufacturers can build to and are building to the standard today." 55 To this end, the Commission instituted five reforms to the CableCARD regime that, it hoped, would get the process back on track and produce a competitive retail

49 Commercial Availability III, supra note 3, ๆ 4.

50 Id. If 4; see also AllVid NOI, supra note 2, I 10 (referring to the CableCARD, the FCC declared, "most manufactures [sic] have abandoned the technology").

51 AllVid NOI, supra note 2, at 4301-02 (Baker, Comm'r, concurring).

52 Commercial Availability III, supra note 3, $\uparrow 8$.

53 Id. || 11.

54 Id. ๆ 8.

55 Id. 
market as contemplated by Section $629 .{ }^{56}$

The first step the Commission took was to require cable operators to provide retail devices with access to switched-digital channels (although it did so without specifying the technology that cable operators must use to ensure such compatibility).. In the Commission's view, subscribers "must be able to use the devices they purchase at retail to access all of the linear channels that comprise the cable package they purchase." ${ }^{8}$ Thus, reasoned the Commission, "[p]roviding retail navigation devices and leased navigation devices with equivalent access to linear programming at an equivalent service price is essential to a retail market for navigation devices."

Next, the Commission adopted a requirement that "cable operators prominently list the fee for their CableCARDs as a line item on their websites (readily accessible to all members of the public) and annual rate cards separate from their host devices, and provide such information orally or in writing at a subscriber's request." ${ }^{60}$ Moreover, the Commission ordered that these CableCARD lease fees be uniform across a cable system regardless of whether the CableCARD is used in a leased set-top box or a navigation device purchased at retail. ${ }^{61}$ Finally, the Commission was "not convinced" that "cable operators [we]re not subsidizing the costs of leased set-top boxes with service fees." ${ }^{162}$ As a result, the Commission adopted a rule requiring cable operators to reduce the prices of packages that include set-top box rentals by the cost of a set-top box rental for customers who use retail devices, and prohibiting cable operators from assessing service fees on consumer-owned devices that are not imposed on leased devices. ${ }^{63}$ According to the Commission, these price reductions must reflect the portion of the package price that is "reasonably allocable" to the device lease fee. ${ }^{64}$

Third, the Commission ruled that "the best means of assuring the development of a retail market for navigation devices is to require cable operators to allow subscribers to self-install CableCARDs." In addition, the Commission made it easier for consumers to file complaints with the Commission, citing examples in the record where consumers had to schedule multiple appointments with the cable company to install a CableCARD purchased from a third-

$\begin{array}{ll}s 6 & \text { Id. } \\ 57 & \text { Id. } \mid 13 . \\ 58 & \text { Id. } \mid 14 . \\ 59 & \text { Id. } \\ 60 & \text { Id. } \mid 19 . \\ 61 & \text { Id. } \\ 62 & \text { Id. } \\ 63 & \text { Id. } \\ 64 & \text { Id. } \\ 65 & \text { Id. } \mid 26 .\end{array}$


party retail outlet. ${ }^{66}$ In the Commission's view, the "need to schedule multiple installation appointments unquestionably is an impediment to realizing a competitive retail market for navigation devices" and, as such, believed that "Congress's intent in adopting Section 629 was to ensure that cable operators treat retail navigation devices in the same manner that they treat leased navigation devices." $" 67$

Fourth, the Commission mandated that cable operators provide multi-stream CableCARD by default, unless a subscriber expressly requests a single-stream CableCARD. ${ }^{68}$ In the Commission's view, such a requirement will ensure the development of a retail market for navigation devices in that such a mandate "will conform more closely with the concept of common reliance, provide improved customer experience, and impose little, if any, costs on the industry."

Fifth, the Commission took steps to update and streamline CableCARD device certification. In particular, the Commission both modified its rules to reflect updated testing procedures and formally prohibited "CableLabs or other qualified testing facilities from refusing to certify [Unidirectional Digital Cable Products] for any reason other than a failure to comply with the conformance checklists referenced" ${ }^{70}$ under current rules. However, the Commission observed that these rule changes did little more than codify the certification process as it exists today."

Notably, all the FCC's actions appear to view the CableCARD's failure as a result of limitations in its operational parameters. Never has the agency considered that its proposals are being impeded by the underlying economics of the equipment-service relationship in multichannel video markets. This omission is important. If CableCARD's defects lie in its inherent inefficiency relative to self-supply, then solving the problems outlined by the FCC will not produce a successful alternative to the CableCARD of the past. The theoretical analysis, infra, indicates that even if the commercially- and self-supplied settop boxes are identical, the commercial model may be relatively inefficient, imposing significant implementation costs without any offsetting benefits. Moreover, if changes to the CableCARD regime, or adoption of the proposed AllVid approach, cannot resolve the operational defects identified, then failure of AllVid is near certain as the regulatory approach is burdened with both inefficiency and operational shortfalls. In fact, with rapidly evolving technology, it

Id. $\uparrow 28$.

Id. 729.

68 Id. ๆ 33. A multi-stream cable card permits multiple channels to be decoded, permitting, for example, a DVR to record one channel while another channel is being watched. Id. II 30 .
Id. ๆ 33 .
Id. $\$ 37$.
Id. 
is possible that the principle defect in CableCARD and AllVid is the mere act of defining the device, in that by defining the device the FCC locks in a technological standard that will soon be outdated.

\section{The AllVid NOI}

In the FCC's AllVid NOI, the agency takes a slightly different approach to explain why CableCARD failed and why the AllVid approach is required. According to the Commission, the "limited interest in purchasing retail devices that can access MVPD services" is attributable to "two fundamental defects." First, the Commission believes that "with few exceptions retail navigation devices are unable to provide functionality beyond that available in devices that subscribers can lease from their providers and often are unable to access many of the MVPD services that leased set-top devices are able to access."73 Second, the Commission believes that "as a general matter a retail navigation device purchased for use with one MVPD's services cannot be used with the services of a competing MVPD."74 Again, both explanations for the CableCARD's failure are operational characteristics of the device. Notably, the FCC provides no explanation as to why its AllVid mandate will successfully resolve these operational defects or, more importantly, how AllVid is more future-proof than the CableCARD. Moreover, the FCC has yet to consider the possibility that the failure of the CableCARD may be the consequence of powerful and legitimate economic forces working against its success.

To remedy these alleged defects, the FCC chose to dig in rather than reconsider; that is, the agency proposes merely to amplify the CableCARD to remedy its operational shortcomings. This leads the agency to the AllVid approach, which seeks to:

[P]lace the network-specific functions such as conditional access, provisioning, reception, and decoding of the signal in one small, inexpensive operator-provided adapter, which could be either (i) a set-back device-which today could be as small as a deck of cards--that attaches to the back of a consumer's television set or set-top box, or (ii) a home gateway device that routes MVPD content throughout a subscriber's home network. The adapter would act as a conduit to connect proprietary MVPD networks with navigation devices, TV sets, and a broad range of other equipment in the home. The AllVid adapter would communicate over open standards widely used in home communications protocols, as outlined below, enabling consumers to select and access content through navigation devices of their choosing purchased in a competitive retail market. MVPDs would, of course, be free to participate in the retail market by offering navigation devices for sale or lease to consumers, but those devices would be separate from the adapter and marketed separately. ${ }^{75}$

Id.

Id. $\mid 22$. 
The AllVid adapter is conceptually identical to the CableCARD in that its primary purpose is to separate conditional access from the other functions of the set-top box. As such, the FCC's general approach to Section 629 is largely unchanged by AllVid. Unfortunately, although the FCC again promises that AllVid will be different and that a vibrant and innovative retail market is just around the corner, ${ }^{76}$ there is no compelling evidence that AllVid will succeed where the CableCARD has failed. As we show infra, the economic factors that killed the CableCARD are likewise working against the FCC's aggressive AllVid approach, so that AllVid is likely to follow the same path to costly failure. With rapidly evolving technology, success is unlikely for any regulation that, by its very nature, locks in a particular technology. Of this, the CableCARD is an archetype.

\section{Other Explanations for CableCARD's Failure}

Notwithstanding the preceding two sections, the Commission has in various other forums also set forth one other explanation for the failure to realize the goals of Section 629: MVPD foot-dragging. For example in the AllVid NOI, the Commission specifically stated that it wants to create a regime wherein device manufacturers are encouraged "to develop and introduce innovative smart video devices without being deterred by the need to consult with MVPDs." FCC Commissioner Michael Copps echoed a similar sentiment in his statement to the AllVid NOI, arguing:

The path to the retail market has been, for many reasons, obstructed at nearly every turn. Something is clearly not working as intended when consumers encounter such disparities between the cost, installation and support of CableCARD devices for those who purchase a retail device and for those leasing the cable provider's set-top box. ${ }^{78}$

And Commissioner Mignon Clyburn apparently holds a similar view, noting:

The time has undoubtedly arrived for us to examine the potential for any electronics manufacturer to offer smart video devices at retail that can be used with the services of any MVPD. In addition, given that the current process for obtaining MVPD certification is so cumbersome and expensive, I am eager to explore ways in which such manufacturers can forego unnecessary coordination and negotiation with MVPDs. ${ }^{79}$

The sentiment that the cable industry intentionally sabotaged CableCard is

76 Id. The Commission specifically states that the new AllVid model will, inter alia, "spur the development of a competitive retail market in navigation devices, thus providing subscribers with viable alternatives to leasing or buying a set-top box from their MVPD" and "drive down retail prices for devices used to access MVPD services without increasing the prices of those services." Id. ๆ 23.

77 Id. \ 23 (emphasis added).

78 Id. at 4296 (statement of Comm'r Copps).

79 Id. at 4300 (statement of Comm'r Clyburn). 
widely held. For example, the left-leaning political interest group Free Press claims that the "cable industry played a prominent role in impeding the potential success of CableCard, a fact often brought to the Commission's attention." Similarly, Professor Marvin Ammori, former General Counsel of the Free Press, argues that CableCard failed because MVPDs "generate huge fees from renting these boxes because they dominate the market for them and have made it difficult for consumers to purchase boxes from any independent company." "Likewise, Public Knowledge argues that the failure of CableCard was not "technical or economic, but behavioral" because "MVPDs have consistently attempted to keep 'foreign devices' from their networks." be left out, Pennsylvania State Professor Rob Frieden argues that, "Cable operators have largely thwarted the Congressional mandate to give consumers alternatives to the operator-leased devices." 83

Such views of the matter are questionable in many respects. First, the FCC mostly regulates the prices of the set-top box at cost. ${ }^{84}$ Furthermore, the agency seems more concerned that equipment prices are subsidized rather than marked up well above costs. ${ }^{85}$ Therefore, the "huge fees" point is invalid to the extent that it possesses a market power connotation. Second, there is neither evidence nor argument supporting the notion that the set-top box offers any increase in market power to the cable industry. ${ }^{86}$ As such, there is no reason to suspect that the industry's behavior with respect to the set-top box is either anticompetitive or anti-consumer. Third, to the extent that the industry has impeded the CableCard's development, such efforts may be driven by legitimate business and social concerns. Indeed, the FCC freely admitted that the CableCard regime

80 In re Video Device Competition; Implementation of Section 304 of the Telecommunications Act of 1996: Commercial Availability of Navigation Devices; Compatibility Between Cable Systems and Consumer Electronics Equipment, Comments of Free Press, MB Docket No. 10-91; CS Docket No. 97-80; PP Docket No. 00-67, at 3 (July 13, 2010) (accessible via FCC Electronic Comment Filing System).

81 Marvin Ammori, Copyright's Latest Communications Policy: Content-Lock-Out and Compulsory Licensing for Internet Television, 18 COMMLAW CONSPECTUS 375, 388 (2010).

${ }_{82}$ In re Video Device Competition; Implementation of Section 304 of the Telecommunications Act of 1996: Commercial Availability of Navigation Devices; Compatibility Between Cable Systems and Consumer Electronics Equipment, Comments of Pub. Knowledge \& New American Found., MB Docket No. 10-91; CS Docket No. 97-80; PP Docket No. 0067, at 6 (July 13, 2010) (accessible via FCC Electronic Comment Filing System) (citing Jonathan E. Nuechterlein \& Philip J. Weiser, Digital Crossroads: American TeleCOMMUNICATIONS POLICY IN THE INTERNET AGE 57-58 (2005)).

83 Rob Frieden, Lock Down on the Third Screen: How Wireless Carriers Evade Regulation of Their Video Services, 24 BERKELEY TECH. L.J. 819, 834 (2009).

84 Commercial Availability I, supra note 13, ๆ 88 (the Commission noted that Congress, in Section 623(b)(3), made clear that equipment used to deliver regulated services must be priced to the consumer at cost).

85 Id. 971 85-87.

${ }^{86}$ See discussion infra Part V Section A. 
might lead to higher costs and prices for equipment. ${ }^{87}$ Under this "foot dragging" theory, a legitimate question to contemplate is whether the industry should be condemned for impeding the CableCard or whether the FCC should be condemned for mandating it. The answer lies in the relative efficiency of self-supply to regulatory-induced commercial supply, and whether the incentives of the MVPDs in this regard can be trusted. These questions will be addressed in the following text.

\section{THE ECONOMICS OF THE SET-TOP BOX}

Multichannel video providers, such as cable and satellite television operators, are in the business of selling subscriptions to multichannel video services. ${ }^{88}$ In most cases, these services require that a piece of equipment, a settop box, be located at the consumer's home or business. The primary purpose of this box is to convert the video signal (in some cases a scrambled signal for security) to a standardized output accepted by consumer premises equipment (i.e., television sets); the boxes are also used to order and provision video-ondemand, display channel guides, and some other features. These set-top boxes are manufactured by consumer electronics manufacturers (e.g., Pace, Cisco, Motorola, Arris, and so forth) and acquired by consumers from their chosen MVPD. MVPDs are not vertically integrated into the manufacturing of such equipment. ${ }^{89}$ A monthly fee for the box (about \$7-10 per month), which typically includes an "insurance" service as well, since defective equipment is typically replaced without fee, is charged for the box." Thus, this "insurance"

87 Commercial Availability III, supra note 3, ๆ 4.

88 DirecTV, Annual Report (Form 10-K), 3 (Feb. 25, 2010) (accessible via SEC Electronic Filing System) ("We are a leading provider of digital television entertainment in the United States and Latin America. Our two continuing business segments, DIRECTV U.S. and DIRECTV Latin America, which are differentiated by their geographic location, are engaged in acquiring, promoting, selling and/or distributing digital entertainment programming via satellite to residential and commercial subscribers"); Comcast Corp., Annual Report (Form 10-K), 1 (Feb. 23, 2010) (accessible via SEC Electronic Filing System) ("We are a leading provider of video, high-speed Internet and phone services ('cable services'), offering a variety of entertainment, information and communications services to residential and commercial customers") [hereinafter Comcast, Annual Report].

89 However, it is worth noting that today most DBS-related equipment is MVPD branded. See Competition and Consumer Choice in the MVPD Marketplace, Including an Examination of Proposals to Expand Consumer Choice, such as A La Carte and Theme-Tiered Offerings: Hearing Before the H. Subcomm. on Telecomm. and the Internet of the H. Comm. on Energy and Commerce, 108th Cong. 2 (2004) (statement of Rep. Fred Upton, Chairman, Subcomm. on Telecomm. and the Internet), available at http://commens.org/U45Cao.

90 AllVid NOI, supra note 2, ๆ 13. See also DiRECTV, http://commens.org/Vmn3D (last visited Nov. 10, 2012); DisH, http://commcns.org/10hml w8 (last visited Nov. 10, 2012). By comparison, wireless companies typically charge a $\$ 4.99$ monthly premium for replacement of mobile telephone equipment, but this includes a $\$ 50-150$ deductible. AT\&T Mobile In- 
service provided by the MVPD is valuable. For cable operators, the prices are regulated to (some measure of) cost plus a return of 11.25 percent. ${ }^{91}$

In this section, we consider the economic incentives of a multichannel video provider with regard to the set-top box, and discuss how such incentives relate to the implementation of Section 629. In the AllVid NOI, the FCC contends that Section 629 could lead to "[c]ompetition in the manufacturing and distribution of consumer devices" as Congress envisioned. ${ }^{92}$ The alleged benefits of such competition are "innovation, lower prices and higher quality." In light of this view of Section 629, we model price and quality choices of the multichannel video provider with regard to services and boxes. Also, in an effort to address the belief that the multichannel video providers have intentionally frustrated the development of a competitive market for set-top box equipment, ${ }^{94}$ we evaluate the provider's preference for self- versus market-supply of the boxes. The model mimics the typical transaction by assuming a consumer purchases a multichannel video service, which requires the use of a set-top box. Since market power is often argued to drive the behavior of multichannel video providers with regard to the set-top box, we assume the video provider is a monopolist. ${ }^{95}$

\section{A. Basic Theoretical Setup}

We consider the case of a single provider of a service, $S$, produced at a constant per unit cost of $s$. Each consumer decides whether or not to buy the service, depending on his or her valuation of it. In order to obtain the service, however, the consumer must also procure a converter or "set-top box", $B$, and this box can, in theory, be produced or provided either by the multichannel video provider or by an outside "retail market" source. Thus, the service $S$ and

surance, AT\&T, http://commcns.org/WKRekf (last visited Nov. 10, 2012) ("Effective Oct. 4,2011 , the premium will increase to $\$ 6.99$ per enrolled mobile number").

91 See, e.g., Charter Commc'ns, Inc., Annual Report (Form 10-K), 6 (Feb. 26, 2010) (accessible via SEC Electronic Filing System) ("In accordance with FCC rules, the prices we charge for video cable-related equipment, such as set-top boxes and remote control devices, and for installation services, are based on actual costs plus a permitted rate of return in regulated markets.").

92 AllVid NOI, supra note 2, \23.

93 Id.

94 Id.

95 We recognize that MVPDs are not monopolists, as each faces competition from at least two other providers in nearly all geographic areas. DirecTV and Dish Network have nearly ubiquitous coverage in the continental United States. See, e.g., In re CoxCom d/b/a Cox Communications Phoenix, Petition for Determination of Effective Competition in Various Arizona Communities, DA 10-2247, MEMORANDUM OPINION AND ORDER (Nov. 29, 2010) (finding that the Phoenix market was "effectively competitive" for purposes of price deregulation under Section 623(1) of the Act because of competing service provided by two DBS providers, DirectTV and Dish Network). 
the box $B$ are perfect complements, neither having value without the other.

Consumers value the $S$ and $B$ combination, and are assumed to buy it if the full price is less than the associated valuation. Letting $p$ be the price paid for service $S$, and $r$ the price of the box $B$, consumer $i$ buys service if $v i>p+r$. We assume there are many consumers, and that their valuations, $v$, are distributed randomly, with cumulative density $F(v)$, marginal density $f(v)$, and with support on the interval $[0, \infty)$. Thus, for the price system $(p, r)$, the proportion of consumers who buy $S$ and $B$ is just $[1-F(p+r)] \geq 0$.

\section{B. Optimal Prices}

We begin by considering the profit-maximizing pricing problem of a service provider who also is the sole seller of the boxes. Thus, consumers must buy both $S$ and $B$ from the service provider, paying prices $p$ and $r$ determined by this provider without restriction. How would such a provider set prices, and would the seller's monopoly power over the box market prove important for the outcome? The well-known answer is "No", due to the perfect complementarity of $S$ and $B$ : the seller gains no advantage from its control of the box market and only the combined price $(p+r)$ is determined by profit maximization. To see this, let $b$ be the per box cost of the seller, and let $s$ be the per customer cost of service. The service provider's profit is:

$$
\pi=[1-F(p+r)](p+r-b-s)
$$

and the firm selects $p$ and $r$ to maximize this expression. This problem, though, is partially degenerate in that only the sum $(p+r)$ is determined by this exercise. In other words, the component prices $p$ and $r$ are individually irrelevant to profit, and the firm can select any combination of $p$ and $r$ that sum to the value determined by the maximization. Thus, let $z=p+r$, and write profit as:

$$
\pi=[1-F(z)](z-b-s),
$$

Maximization of (2) with respect to $z$ yields the following condition:

$$
[1-F(z)]-f(z)(z-b-s)=0
$$

where these expressions are to be evaluated at $z^{*}$, the optimal solution. Thus, any prices $\left(p^{*}, r^{*}\right)$, that satisfy the condition $z^{*}=p^{*}+r^{*}$ are profit maximizing. Let us denote the profit-maximizing profits from $z^{*}$ as $\pi^{*}$. 


\section{Consumer Surplus}

Consumer welfare will be taken to be equal to total consumer surplus in this market. This total surplus is the sum of individual surplus over the mass of consumers purchasing the service. The expression for consumer welfare, $C S(z)$, is given by:

$$
C S(z)=\int_{z}^{\infty}(v-z) f(v) d v
$$

We note that consumers always benefit from a reduction in the total price of service:

$$
\frac{\partial C S}{\partial z}=-[1-F(z)] \leq 0 .
$$

This analysis, although somewhat simple, illustrates several important points, some of which we will turn to now. There are two main features of the model to keep in mind. First, since the service and box are consumed together, consumers care only about the sum of the prices, or $z$. Second, consumers always prefer a lower aggregate price $z$; if $z$ falls, then consumers benefit.

\section{Effect of Regulated Set-Top Box Prices}

In most cases for the cable television industry, the price of the set-top box is regulated at a cost-plus 11.25 percent return. What is the effect of this regulation? Suppose that the regulated price is $r^{\prime}$. Being free to set the price for service, the seller would just set $p^{*}=z^{*}-r^{\prime}$ so that profits and consumer surplus would be unchanged. The single price $p$ is sufficient to extract all available profits for the seller. Note that it is irrelevant what price is set by regulation for the box (such as $r^{\prime}=b$ as in the existing regulation); since the full price is $z=p$ $+r$, any modification to $r$ can be offset by a corresponding change in $p$.

\section{E. Competitive Supply}

We consider next the existence and effects of a competitive alternative supply of set-top boxes. Suppose that this competitive market supply is infinitely elastic at a price of $r m .{ }^{96}$ The effect of this circumstance on the seller and consumers depends, of course, on what $r m$ is, and particularly whether $r m$ is larger or smaller than $b$, the service provider's cost per box. We assume that the service provider and the competitive suppliers of boxes offer identical boxes, so that the competitive sellers capture the entire box market if $r m<r$, and sell no

96 That is, consumers can purchase all they care to at price $\mathrm{rm}$. 
boxes otherwise. Let $\pi m$ be the service provider's optimal profit with competitive supply price $r m$. We have the following:

Proposition 1: $\pi_{m} \geq \pi^{*}$; MVPD profits are never lower with market supply than self-supply.

Proof. If the service provider sets a price $r<r m$, and sets $p^{*}=z^{*}-r$, then he obtains the profit $\pi^{*}$, so he can always assure himself of this profit level. However, if $r m<b$, then he can do even better. To see this, suppose the seller sets $p_{0}=z^{*}-r m$, and sets $r$ at any level above $r m$, so he sells no boxes. In this case his profit is:

$$
\pi_{0}=\left[1-F\left(z^{*}\right)\right]\left(p_{0}-s\right)
$$

Since $p_{0}>z^{*}-b$, we have $\pi_{0}>\left[1-F\left(z^{*}\right)\right]\left(z^{*}-b-s\right)=\pi^{*}$. Thus, whenever $r m<b$, we have $\pi_{m} \geq \pi_{0}>\pi^{*}$. Q.E.D.

The proof demonstrates that MVPDs may prefer that set-top boxes be provisioned by a commercial market rather than by self-supply if the commercial market can supply such equipment more efficiently than can the MVPDs. In fact, the proof understates the case somewhat, since the pricing policy $p=p_{0}$ described above is not the optimal policy with competitive supply at a price below the service provider's own costs. An optimal pricing rule can lead to profits even higher than those at $p_{0}$ when $r m<b$.

Consider the seller's optimal response to competitive box supply at a price $\mathrm{rm}$ that is below the seller's own cost level $b$. We know from the proof of Proposition (1) that, if $r m<b$, the seller will do better by surrendering the box market to the competitive suppliers. Hence, the total price faced by consumers would be $z=p+r m$ and the revenue received by the service provider per customer would be $(z-r m)$. Formally, the service provider selects $z$ to maximize profit given $r m$ :

$$
\pi\left(z ; r_{m}\right)=[1-F(z)]\left(z-r_{m}-s\right)
$$

This parameterized and unconstrained optimization problem exhibits complementarity in the objective function:

$$
\frac{\partial^{2} \pi}{\partial z \partial r_{m}}=f(z)>0 \text {. }
$$

Thus, the objective function in (7) possesses strictly increasing differences between $z$ and the parameter $\mathrm{rm}$. Standard results in lattice programming imply 
that the optimizing solution will be an increasing function of the parameter $\mathrm{rm} \cdot{ }^{97}$ If we let $z m(\mathrm{rm})$ denote the optimal solution to this unconstrained maximization problem, then we have that $z m(r m)$ is an increasing function. A direct comparison of (2) and (7) yields the immediate fact that $z m(b)$ equals $z^{*}$. Thus, if $r m<b$, we have that $z m(r m)<z^{*}$. Hence, consumers face a lower total price and, by Expression (5), consumer welfare will be higher.

This result, combined with Proposition 1, has the following significance. When the service provider behaves optimally, and efficient competitive suppliers provide the box at a price $r m<b$ (the service provider's box cost), the service provider will welcome the competitive supply, which will increase his profits. Further, the full price of service to the customers is declining in the level of the competitive box cost $\mathrm{rm}$. Thus, any reduction in such costs serves consumers and the firm alike, and the firm has no incentive to block such sales.

\section{F. Incentive to Reduce Set-Top Box Costs and Prices}

In the previous section, we showed that the MVPDs prefer a commercial market for set-top boxes when such an arrangement is more efficient and leads to lower equipment prices for consumers. We show here that MVPDs likewise will pursue cost reductions that reduce equipment prices to consumers. Noting that $d \pi / d z=0$ at the optimal choice $z^{*}$, simple differentiation shows:

$$
\frac{\partial \pi^{*}}{\partial b}=-\left(1-F\left(z^{*}\right)\right)<0 \text {. }
$$

Thus, the service provider would welcome any reduction in the cost of $B$ (such as a reduction in $b$ to $b^{\prime}<b$, say), since the reduction will result in increased seller profits. The Commission, therefore, should expect video providers to seek low cost and efficient production of their set-top equipment.

It is also the case that a lower cost for set-top equipment increases consumer welfare. Notice that the objective function in (2) exhibits strictly increasing differences between $z$ and $b$. The optimal aggregate price, $z^{*}$, will be an increasing function of box cost:

$$
\frac{\partial z^{*}}{\partial b}>0 \text {. }
$$

We know from Expression (5) that consumer welfare is determined by $z^{*}$. Since lower box costs increase profits, lower total prices, and increase consumer welfare, lower box costs increase overall economic welfare. In the case of costs, therefore, the incentives of multichannel video provider are in line

97 See, e.g., DonALD M. TOPKIS, SUPERMODULARITY AND COMPLEMENTARITY (1998). 
with the interest of consumers and economic welfare. Both the CableCard and AllVid proposals have been based on the idea that a retail market for such set top equipment may reduce the cost of such devices, but this argument implies that the multichannel video providers are not interested in cost reductions, which we have just shown is a false view.

\section{G. Incentive to Innovate}

Another argument used by the Commission to support both its CableCard and AllVid creations is that such actions will "spur innovation." this reasoning is that multichannel video providers do not have adequate incentive to innovate. We turn now to the important problem of market innovations that increase consumer valuation of the service $S$, rather than decreasing the cost of the box. Although there are many ways one might represent such a change in valuation due to some innovation in service (e.g., proportional increases in values, first order dominating shifts in the valuation distribution, and so on), the simplest and most obvious way is merely to assume that the new innovation raises all consumers' valuation levels by some positive amount " $e$ " (i.e., an enhancement). Although simple, this formulation allows for a very clear view of the effects of such value enhancement on the welfare of consumers and the service provider when both behave optimally.

With the enhancement $e$, consumer $i$ will buy service if $v i+e>p+r$. This is equivalent to the inequality $v i>p+(r-e)$. Thus, technically speaking, we can directly translate the enhancement into our previous analysis simply by absorbing it into the box price $(r)$. Hence, let $r e=(r-e)$ and define $z=p+r e$. The service provider's profits are:

$$
\pi\left(z ; r_{e}\right)=[1-F(z)]\left(z-r_{e}-s\right)
$$

Next, we let $z e(r e)$ denote the maximization of this profit function with respect to $z$, given the parameter re. Noting the exact similarity between (11) and (7), we can use (8) to conclude immediately that $z e(r e)$ is an increasing function. Since $r e<r$ and $z^{*}=z e(r)$, we have that $z e(r e)<z^{*}$. Recalling from (5) that $C S$ is a decreasing function, we conclude that $C S(z e(r e))>C S\left(z^{*}\right) \cdot{ }^{99}$ Consumer welfare increases if the market provides a technologically enhanced box.

The service provider's profit also increases when the competitive market provides an enhanced box. Since $z e(r e)$ is optimal and $r e<r$, we have that

98 Commercial Availability III, supra note 3, at 14,708 (statement of Chairman J. Gena-

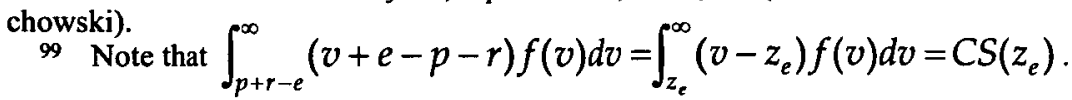




$$
\pi\left(z_{e}\left(r_{e}\right) ; r_{e}\right) \geq \pi\left(z^{*} ; r_{e}\right)>\pi\left(z^{*} ; r\right)=\pi^{*}
$$

The service provider has no incentive to block the competitive market's enhanced box as it clearly provides greater profit opportunities. Any enhancement that increases consumer valuation is seen to result in both increased seller profits and increased buyer welfare. Thus, if such an enhancement were available, then the service provider would welcome its introduction and consumers would benefit as well.

We have established that MVPD providers will actively pursue cost reductions and innovations in a manner consistent with consumer interests. Of course, all available cost reductions or imaginable innovations may not be pursued, since in some cases the two may be at odds: a better box may be a more costly box; or, a cheaper box may be a less sophisticated box. In any case, the tradeoffs are apparent. If the innovation increases demand sufficiently enough to warrant a higher cost (and thus a higher price), then it will be pursued. If not, then it will not. ${ }^{100}$ While we do not model variations in the capabilities of set-top boxes (e.g., high-definition functionality, digital video recording, and so forth), MVPD providers offer a variety of boxes, with different costs and prices that suit the needs of particular customers. ${ }^{101}$

\section{EVIDENCE AND ANECDOTES}

In the previous section, we presented a formal economic analysis of set-top boxes that provides a number of significant insights. In contrast to the common view, our theoretical analysis reveals that the set-top box conveys no market power to the MVPD and that the MVPD has no anticompetitive preference for

100 See, e.g., George S. Ford, Thomas M. Koutsky \& Lawrence J. Spiwak, The Efficiency Risk of Network Neutrality Rules, Policy BulletiN No. 16 (Phoenix Ctr. for Advanced Legal \& Econ. Pub. Policy Studies, Washington, D.C.), May, 2006, at 9, available at http://commcns.org/V8i33R. As is well known, the private gains from innovation may be less than the social gains. As such, firms typically under-invest in innovation. This underinvestment is a general phenomenon and is not limited to the cable industry or the set-top box. See generally T. Randolph Beard, George. S. Ford, Thomas. M. Koutsky \& Lawrence. J. Spiwak, $A$ Valley of Death in the Innovation Sequence: An Economic Investigation, $18 \mathrm{RE}-$ SEARCH EVALUATION 343, 343-56 (2009) (regarding the general problem of underinvestment in innovation). To our knowledge, there is no evidence (of which we are aware) to suggest that the general incentive to innovate in the multichannel video industry is diminished relative to that in other industries due to the divergence of private and social gains.

101 See In re Video Device Competition, Implementation of Section 304 of the Telecommunications Act of 1996, Commercial Availability of Navigation Devices, Compatibility Between Cable Systems and Consumer Electronics Equipment, Comments of Cisco Systems, Inc., M.B. Docket No. 10-91, CS Docket No. 97-80, PP Docket No. 00-67, at 11 (July 13, 2010), available at http://commcns.org/YbLoiH (accessible via FCC Electronic Comment Filing System) (recognizing "there has been an explosion in the number and use of over-the-top video devices and services over the past several years"). 
self-supply. The MVPD simply prefers whatever market arrangements most efficiently deliver the equipment to its consumers. Our analysis reveals that if the equipment can be made cheaper and offered at a lower price, then the MVPD will embrace the cost reduction. Also, if the set-top devices can be made more innovatively to increase the value to consumers, then the MVPD is incentivized to implement that innovation. These theoretical results directly conflict with the common view of the service-equipment relationship in the multichannel video market, which is the view held by the FCC as it formulates its Section 629 strategy. ${ }^{102}$ However, this "common view" is devoid of any economic foundation, and is, thus, dubious.

In this section, we provide evidence and anecdotes supporting the general themes of our theoretical analysis. A lack of data does not permit a formal econometric analysis of our theory. Nevertheless, there is good evidence to suggest that the theory has value, and we present some of that evidence below.

\section{A. Equipment is Not a Tool for Surplus Extraction}

Some potent evidence supporting this theory comes from the archetype equipment model specified by the FCC-the broadband cable modem. ${ }^{103}$ Indeed, the National Broadband Plan observes, inter alia, that broadband modems are an "analog for innovation in set-top boxes" because a cable modem "provides all network functions" and "connects via a standardized Ethernet port to numerous devices consumers can buy at the store-including PCs, game consoles, digital media devices and wireless routers." 104 In so doing, argues the Commission, "innovation can happen on either 'side' of that device without affecting the other side." ${ }^{105}$ Similarly, in the AllVid NOI, the agency argues, "Ethernet and the IEEE 802.11 standards have led to nationwide interoperability for customer data networks while allowing broadband service providers to deploy differing proprietary network technologies." ${ }^{106}$ Plainly, the FCC believes that the retail acquisition of the set-top box can and should be like the broadband modem.

What is interesting about the FCC's analogy is that, like set-top boxes, the broadband modem is a piece of equipment provided by broadband providers (including MVPDs) that is inextricably linked to the provider's service. If, as some claim, the self-supply of equipment is an important instrument for surplus extraction, then we would expect to see the MVPDs (and other broadband

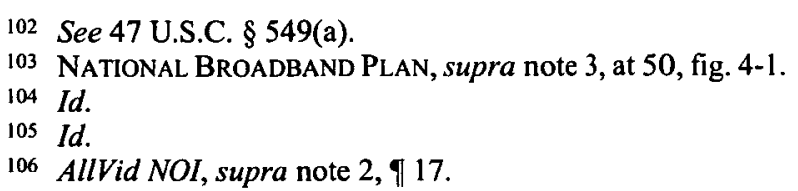


providers) behave similarly with regard to the modem as they do the set-top box. Yet, the MVPDs who also provide broadband services permit, without interference or constraint, the customer's acquisition of broadband modems in the commercial market. Both cable and DSL broadband modems can be purchased at big-box stores such as Best Buy. ${ }^{107}$ This fact indicates that the equipment itself is not a source of market power for MVPDs, as our theory implies. Furthermore, most consumers continue to lease cable modems despite the presence of a competitive retail market for such devices. ${ }^{108}$ It appears, from the FCC's own analogy, that the demand for commercial alternatives to leased equipment is low.

Why, then, are there substantially more cable modem options for consumers at retail than there are with the set-top box? ${ }^{109}$ One explanation for that difference is that, although a commercial market is equally as efficient as self-supply for broadband modems, self-supply, all things considered, is the more efficient arrangement for set-top boxes. The relative efficiency of self-supply may arise from conditional access and security and theft concerns, some of which are driven by contractual relationships with copyright owners. ${ }^{110}$ Such concerns are not generally relevant for broadband modems."

Analogies are often useful, but the FCC's search for a suitable analogy for the set-top box-whether it is the telephone or the data modem-is largely pointless. The relative efficiency of self-supply versus commercial-supply of equipment may vary substantially across industry sectors and services. Different outcomes should be expected and regulatory-induced homogeneity renders no apparent benefit. The agency should then, at a minimum, study the root causes of these differences, without pre-judgment, and use this knowledge to

107 In fact, two of the authors of this paper are using their own personal cable modem to receive broadband service from cable operators.

108 NPB Public Notice, n.3-4.

109 Id.

110 AllVid NOI, supra note 2, I 22; In re Video Device Competition; Implementation of Section 304 of the Telecommunications Act of 1996: Commercial Availability of Navigation Devices; Compatibility Between Cable Systems and Consumer Electronics Equipment, Comments of $A T \& T$, Inc., MB Docket No. 10-91, at $51-57$ (July 13, 2010) (accessible via FCC Electronic Comment Filing System); In re Video Device Competition; Implementation of Section 304 of the Telecommunications Act of 1996: Commercial Availability of Navigation Devices; Compatibility Between Cable Systems and Consumer Electronics Equipment, Reply Comments of DIRECTV, Inc., MB Docket No. 07-269, at 16-23 (June 8, 2011) (accessible via FCC Electronic Comment Filing System).

111 National BroAdBand PLAN, supra note 3, at 50, fig. 4-1 (discussing that the agency itself concedes that with a cable modem, "PC manufacturers do not need to sign nondisclosure agreements with broadband service providers, license any intellectual property selected or favored by broadband service providers or get approval from any broadband service providers or any non-regulatory certification bodies to develop or sell their PCs at retail or enable consumers to attach them to service provider networks through the interface device"). 
guide policy rather than simply presume the outcome in one market will be transferable to another.

\section{B. Now You See It, Now You Don't in DBS}

In its Navigation Devices Order, the FCC decided that satellite video providers, such as DirecTV and EchoStar, were not required to comply with the FCC's separate security rules. ${ }^{112}$ The Commission's rationale is particularly important to review in detail:

[D]ifferences in the marketplace for DBS equipment, where devices are available at retail and offer consumers a choice, as compared to equipment for other MVPD services, particularly cable operators, provide justification for not applying the rule requiring separation of security functions to DBS service. We are reluctant to implement a rule that could disrupt an evolving market that is already offering consumers the benefits that derive from competition. In the DBS environment, there are three service providers and at least ten equipment manufacturers competing to provide programming and equipment to consumers. The equipment is available at retail stores. The result, over a relatively short time frame, has been lower equipment prices, and enhanced options and features. Requiring DBS providers to [comply with the separate security rules] would serve a limited purpose and disrupt technical and investment structures that arose in a competitive environment. ${ }^{113}$

At the time of this decision, it was true that DBS equipment was made by a wide variety of manufacturers and could be purchased in numerous retail outlets. ${ }^{14}$ Not today. Nearly all DBS equipment is now MVPD-branded, though still available at big box retailers and smaller outlets. However, when a consumer purchases the DBS service, the equipment is treated as "leased."115 The evolution of the service-equipment relationship in DBS is highly relevant. The move from a commercial to a leased self-supply model in the DBS sector "arose in a competitive environment." 16

As such, the evidence points to the conclusions that the self-supply model is relatively more efficient than the retail model, since inefficiency is not tolerated by competition. We recognize this is but one interpretation of these facts, but it seems apparent that some consideration by the FCC as to the causes of

112 Id.

113 Commercial Availability I, supra note 13, \64.

114 Id. $\$ 65$.

115 Linda Moss, DirecTV's New Lease on Life, Multichannel News (Jan. 23, 2006); DirecTV Group Inc., Annual Report (Form 10-K), at 4 (Feb. 26, 2009) ("Most set-top receivers provided to new and existing subscribers are leased subsequent to the introduction of the lease program on March 1, 2006"); Dish Network Corp., Annual Report (Form 10-K), at 4 (Mar. 1, 2010) ("We incur significant upfront costs to provide our new subscribers with in-home equipment, including advanced HD and DVR receivers, which most of our new subscribers lease from us. While we seek to recoup such upfront equipment costs mostly through monthly fees, there can be no assurance that we will be successful in achieving that objective.").

116 Commercial Availability I, supra note 13, ๆ 64. 
this significant change in the service-equipment relationship in the DBS sector is warranted before substantially expanding the scope of its Section 629 efforts.

\section{The Cost of Set-Top Boxes}

A reduction in cost for set-top boxes is significant for the industry. Cable operators' largest annual capital expense is consumer premises equipment (video boxes, VoIP equipment, and broadband modems), representing more than half of total capital expenditures. Lease fees do not always recover these costs. ${ }^{117}$ Table 1 provides the figures for Comcast and Charter Communications. ${ }^{118}$ As explained by Charter, "[d]uring 2010, we expect capital expenditures to be approximately $\$ 1.2$ billion. We expect the nature of these expenditures will continue to be composed primarily of purchases of customer premise equipment related to telephone and other advanced services." 19 Our theory shows that firm profits rise when set-top box costs fall, so the industry will actively seek to minimize the cost of the equipment and, in turn, minimize the price to consumers. Given the significant share of capital costs, cost reductions are likely to be significant to both MVPDs' profits and their consumers' wellbeing.

Table 1. Distribution of Capital Expeditures

Comcast

Customer Premises Equip-
ment
Scalable Infrastructure
Line Extensions
Upgrade/Rebuild
Support Capital

Commercial Services

Total Capital Expenditures
$2,934(58 \%)$

$855(17 \%)$

$120(2.4 \%)$

$421(8.4 \%)$

$356(7.1 \%)$

$351(7 \%)$
Charter

$593(52 \%)$

$216(19 \%)$

$70(6 \%)$

$28(2.5 \%)$

$227(20 \%)$

Source: Comcast and Charter 2009 Form 10-K.

There is more empirical evidence to support this conclusion. As observed in the AllVid NOI, the FCC has granted waivers "to cable operators in financial

117 See, e.g., Dish Network Corp., Annual Report, supra note 115, at 4.

118 Comcast, Annual Report, supra note 88; Charter Commc'ns, Inc., Annual Report, supra note 91.

119 Charter Commc'ns, Inc., Annual Report, supra note 91, at 50. 
distress"120 and in cases rendering "substantial public interest benefits by significantly reducing cost."121 Plainly, if waivers are granted in cases of financial distress and provide benefits in the form of reduced costs, then the existing CableCard regime must be costly; cable companies are better off financially with a waiver, in part because they can offer lower priced equipment to consumers to expand their subscriptions. As noted above, the Commission admitted before the D.C. Circuit that its integration ban may increase the cost of settop boxes in the short-run. ${ }^{122}$ The agency's promise of an offset in the form of lower prices and more innovation never materialized, but the higher prices and costs did.

\section{The Industry Supports a Commercial Market}

While the MVPD industry is uniformly against the FCC's strict control of set-top box design and evolution by way of its AllVid mandate, the industry does not appear to be opposed to a commercial market for set-top equipment, or even opposed to some of the functionality embedded in the AllVid device. For example, the National Cable \& Telecommunications Association ("NCTA") states,

Our industry is committed to providing content to consumers where and when they want it, on all possible consumer devices, and for those devices to be innovative platforms for new applications. We want consumers to be able to buy video devices at retail and to know that cable content can be among their video sources. ${ }^{123}$

The NCTA outlines seven principles to which cable operators are committed, including, but not limited to, the principle that "consumers should have the option to purchase video devices at retail that can access their multichannel provider's video services without a set-top box supplied by that provider."124 Included in its lists of potential solutions is "delivery from the 'cloud' without the need for any dedicated receiving device."125

The industry does, however, comprehend the complexity of the issue. For example, as the NCTA states,

[W]ell-crafted solutions must account for how content providers license programming

120 AllVid NOI, supra note 2, ๆ 9.

121 Id.

122 Comcast Corp, FCC, 526 F.3d 763, 767 (D.C. Cir. 2008).

123 In re Video Device Competition, Implementation of Section 304 of the Telecomm. Act of 1996, Commercial Availability of Navigation Devices, Compatibility Between Cable Systems and Consumer Electronics Equipment, Comments of the Nat'l Cable and Telecomm. Ass'n. on the Commission's Notice of Inquiry, MB Docket No. 10-91, CS Docket No. 97-80, PP Docket No. 00-67, at Exhibit A (July 13, 2010) [hereinafter Comments of Nat'l Cable and Telecomm. Ass'n].

124 Id. at 2.

125 Id. at 30 . 
to distributors, how all video providers associate security, transactional, advertising, and promotional elements with their video products, how consumer electronics manufacturers and retailers build support for new product categories, what consumers are willing to buy rather than lease, and how to assure that solutions do not inadvertently handicap future innovation. Solutions must also assure that, as Internet content is delivered over the television, it is afforded all of the copyright protections that apply when it is delivered to the home computer. ${ }^{126}$

Considering these (and other) complexities related to the technical delivery of modern multichannel video services, it is not difficult to see why the selfsupply of set-top equipment is widely-viewed in the industry as more efficient than a commercial market.

These statements are, as indicated from elements of the cable television industry, an industry many feel has intentionally given the CableCard short shrift. There will surely be those that view these industry comments as disingenuous. However, our economic analysis encourages an alternative view, perhaps a better explanation for the alleged difference between stated intent and behavior with regard to set-top boxes is that the technical and practical nuances of creating a commercial market for such equipment are greatly underappreciated by industry outsiders, including the FCC.

An MVPD provider's line of business is selling video. As noted above, the MVPDs are now exploring and implementing ways to deliver their programming over an increasing number of devices (iPad, XBox, Wii, among others) and using a wide variety of formats. Improving the set-top box, getting it into the hands of consumers at lower prices, and possibly even eliminating the box altogether, is plainly in the interest of the MVPD provider as long as such actions increase the consumers' willingness to pay for video services. In this light, opposition to AllVid is not about the device's proposed functionality, or about a competitive market for equipment. The opposition, it appears, arises from ham-handed regulatory mandates for particular technological choices that limit innovation and tend to raise the price for equipment (as did the CableCard). Higher prices for equipment, absent an offsetting quality increase, are not good for consumers or for MVPD providers.

\section{E. Incentive to Innovate}

Above we presented an economic model showing that the incentives of the multichannel video provider with respect to the set-top box are compatible with the desires of consumers and economic welfare in terms of innovation. This view is consistent with the financial reporting of the cable industry. The largest cable operator, Comcast, stated in its Form 10K filing, "[w]e are focusing our technology initiatives on extending the capacity and efficiency of our

126 Id. Exhibit A. 
networks, increasing the capacity and functionality of advanced set-top boxes, developing and integrating cross-service features and functionality, and developing interactive Internet protocol-based services." 127 In its annual financial filings, Comcast also makes clear the harms to innovation that would flow from an aggressive regulatory approach to implementing Section 629: "Some of the alternative approaches [to Section 629], if adopted, could impose substantial costs on us and impair our ability to innovate." ${ }^{128}$ Since the set-top box is an essential component of many MVPD services, improving the set-top box is an important goal of the industry. Giving customers high-cost, low-quality set-top boxes reduces the demand for service, and thus reduces profits. As we have shown above, even a monopolist would not pursue such a strategy. Moreover, there is no good reason to suspect that outside vendors will have more interest in innovation than multichannel video providers since the video providers directly earn profits from the business, so a forced commercial market for set-top boxes is unlikely to generate much benefit in this regard. ${ }^{129}$

\section{CAVEAT: THE CASE OF VARIABLE PROPORTIONS}

The analysis presented above assumes a one-to-one type consumer demand for boxes $B$ and service $S$. Although this appears to be a fairly restrictive assumption, the applicability of the analysis to the case of a "continuous" number of boxes can be easily demonstrated. The number of boxes used by a household may be some number greater than one. ${ }^{130}$ Suppose that we retain our demand set-up, with the addition of a representative consumer model for set-top box demand. The immediate consequence of this formulation is that, while consumers vary, as before, in their valuations of service ( $v$ varies as above), consumers have identical demands for boxes or, somewhat less restrictively, consumer welfare resulting from changes in box prices (or qualities) can be sufficiently analyzed using the widely-applied representative consumer formulation. This approach avoids the technical complications that necessarily arise when we have differentiated households that exhibit possibly correlated valuations for service and boxes. (It is quite unclear, a priori, how these preferences should be represented in this more complex case.)

Given this set-up, a reinterpretation of the meaning of the box price $r$ and the enhancement variable $e$ allows us to generalize the previous results in each,

127 Comcast, Annual Report, supra note 88, at 3.

128 Id. at 9.

129 Cf. Ronald S. Burt, Structural Holes and Good Ideas, 110 AM. J. SoclologY 349 (2004) (discussing the source of innovation must rest in the "diversity" logic).

130 Comcast, Annual Report, supra note 88, at 6 ("On average, as of December 31, 2009, each digital video customer had 2.0 digital set-top boxes, including digital transport adapters."). 
particularly when the service provider's box price is regulated. Specifically, it is once again the case that the service provider and consumers would benefit from a reduction in box "price" through competitive supply, and the service provider would not block, but would welcome, a competitive provision of boxes (if at a lower cost than self supply). Again, the incentives of the service provider, and those of consumers and society, would be well aligned.

We assume additional boxes increase the utility of the service by an amount equal to the area under the inverse demand curve $D(q)$, as illustrated in Figure 1. The cases where the box is supplied by the service provider at a costregulated price $(b)$ or provided by a competitive market at a price of $b m$ can be easily compared using our prior framework. Letting $D(Q)=b$ and $D(Q m)=b m$, the enhancement from boxes in each case is given by:

$$
\begin{aligned}
& E=\int_{0}^{Q} D(q) d q \\
& E_{m}=\int_{0}^{Q_{m}} D(q) d q
\end{aligned}
$$

Next, let $r=(b Q-E)$ and $r m=(b m Q m-E m)$. We can now apply the prior analysis to this situation noting that $r m$ is less than $r$ by an amount equal to the shaded area in Figure 1.

Figure 1. Representative Box Market

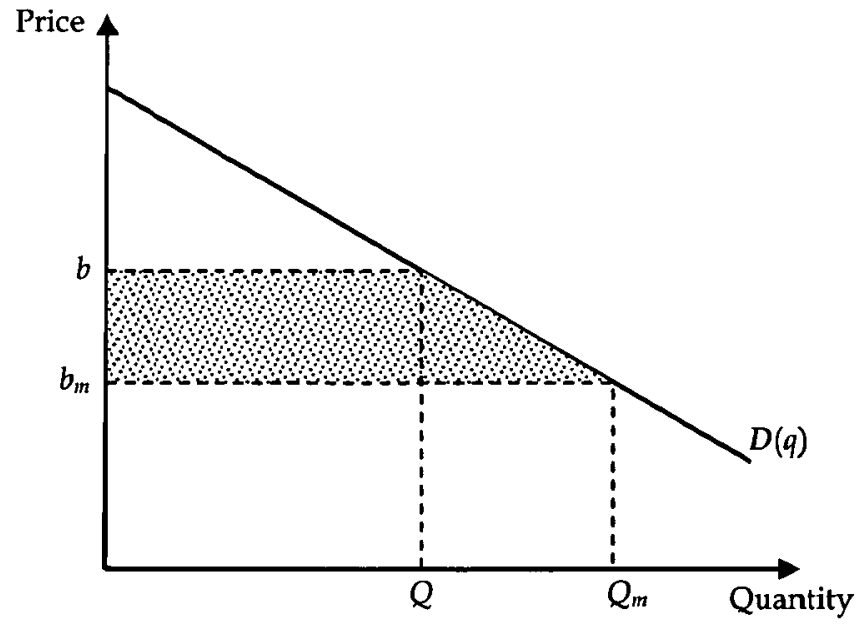


The implication of this finding is immediate. Suppose that a competitive supply of boxes emerges at a box price $b m$ below the service provider's regulated offering. Then the provider voluntarily yields the box market to the entrants, and the result of this action is effectively a reduction in the box "price" $r$, as detailed above. From our prior analysis, we know that this results in increased service provider profits and increased consumer welfare, so social welfare increases. ${ }^{131}$ Consumers respond to the lower box price by buying more boxes, creating an additional benefit to service/equipment consumption.

While the set-top box prices for cable television operators are often regulated, this is not the case for direct broadcast satellite providers. The satellite providers are not subject to rate regulation under the provisions of the 1992 Cable Act or the 1996 Telecommunications Act; nor are they now required to provide separate security functions in the form of a CableCard or similar device. $^{132}$

In the case of continuous demand, the freedom to set both service and box prices gives rise to the potential for price discrimination. ${ }^{133}$ Theoretically, the discriminatory price vector for service and boxes could be anything. How price discrimination would be used in the industry is theoretically ambiguous; it is an empirical question. Fortunately, evidence is available. For satellite video providers, a set-top box is required for each television, and the prices for these boxes are unregulated. As a result, the case for discriminatory pricing leading to high box prices is likely highest in the satellite industry. However, the evidence does not support the use of such practices. For example, as of September 2012, Dish Network provides the standard set-top boxes at no additional charge for some plans. ${ }^{134}$ High Definition boxes are only $\$ 7.00$ per month, which is consistent with pricing in the regulated cable television industry. ${ }^{135}$ DirecTV offers the first receiver free with all service plans. ${ }^{136}$ Notably, prior to 2006 DirecTV did not use a lease program, and a $\$ 5.00$ fee applied to each additional television in the customer's home (each set-top box requires a converter card, so quantity can be measured) ${ }^{137}$ Changing to a lease program did not alter the pricing of additional television outlets, indicating that the set-top box is not a useful tool for implementing price discrimination.

131 See discussion infra Part IV Section E.

132 See 47 U.S.C. \$ 549(b); Commercial Availability I, supra note 13, ๆ 64.

133 For discussion of the FCC's purpose in enacting these rules, see Commercial Availability III, supra note $3, \mathbb{1} 1$.

134 English Special Offers, DiSH NETWORK, http://commens.org/11C76x8 (last visited Nov. 10, 2012).

135 Set Up Your Televisions, Dish NeTwORK (on file with CommLaw Conspectus).

136 English Packages, Direct TV, http://commcns.org/VroaSa (last visited Nov. 10, 2012).

137 See DirecTV, Annual Report, supra note 88, at 50. 


\section{FACT-BASED LEGAL AND ECONOMIC ARGUMENTS FOR SUNSET OF SECTION 629}

Given the above, is there a compelling policy reason for the Commission to continue with its quixotic attempt to try to develop a commercial retail market for set-top boxes? The answer is clearly, no. As noted in preceding sections, the FCC has repeatedly conceded that its "separable security" approach to Section 629 is an uncontested failure, ${ }^{138}$ to try again seems, at this point, to be the triumph of hope over experience. Moreover, the video market is presently undergoing substantial transformation and experiencing rapid innovation. ${ }^{139}$ As such, the timing for a regulatory-mandated technology standard could not be worse. Similarly, using regulation to force a commercial retail market is arguably poorly motivated because providers have not demonstrated anticompetitive behavior with regard to the set-top box. To the contrary, MVPDs are strongly motivated to provide low-cost, high-feature set top equipment to consumers, and regulation is unlikely to lower price, improve quality, or increase innovation. Indeed, the Commission has repeatedly acknowledged that its CableCARD rules increase prices and reduce network deployment. ${ }^{140}$ Perhaps most importantly, AllVid's ultimate failure is virtually inescapable because the commercial market envisioned under Section 629 is, today, inefficient, and markets abhor inefficiency.

We hold no monopoly on skepticism regarding the successful implementation of Section 629. Regarding CableCARD, Commissioner Michael Copps observed, " $[\mathrm{t}]$ he intent, we all recall, was to spur on a competitive retail market to provide consumers more choice. But it didn't happen. In many ways, the outcome of our pursuit has been the opposite of what was intended."141 Commissioner Copps' take on the renewed effort, which he supports, is likewise pessimistic--noting that the AllVid proposal is "a particularly ambitious one"1/2 —and comes with a warning: "I would just caution my colleagues on

138 See discussion infra Part III Section A.

139 AllVid NOI, supra note 2, \13 ("[D]elivery platforms continue to evolve at a rapid pace").

140 Commercial Availability II, supra note 45, \29 ("[W]e believe it is likely that consumers will face additional costs in the short term as a result of the prohibition on integrated navigation devices"); see also Charter Commc'ns, Inc. v. FCC, 460 F.3d 31, 41-42 (D.C. Cir. 2006); Comcast Corp. v. FCC, 526 F.3d 763, 767 (D.C. Cir. 2008) ("[T] he FCC has conceded that the integration ban may impose short-term costs on cable companies and consumers").

141 In re Implementation of Section 304 of the Telecommunications Act of 1996, Commercial Availability of Navigation Devices, Compatibility Between Cable Systems and Consumer Electronics Equipment, Fourth Notice of Proposed Rulemaking, 25 F.C.C.R. 4275, 4326 (Apr. 21, 2010) [hereinafter Commercial Availability Fourth NPRM] (statement of Comm'r Copps).

142 Id. at 4327 (statement of Comm'r Copps). 
how much work and pushing from this Commission will be required to reach the happy world of gateway device availability. .. . [T] he sad saga of the CableCARD illustrates the pitfalls that await us at every corner." 143 Commissioner Copps also suggests that success requires "true private sector-public sector coordination and partnering," yet many in the private sector are opposed to regulatory-mandated technology standards, including MVPDs, programmers and other content suppliers. ${ }^{144}$ Success, therefore, faces significant hurdles. Similarly, Commissioner McDowell observed that "technological innovation continues to outpace the government's ability to keep up" and indicates he will "remain humble about the government's ability to predict the pace and direction of technological developments. If nothing else, our experience in implementing Section 629 should remind us of the value of modesty in rulemaking." 145

Commissioner McDowell goes further by suggesting that given the difficulty of implementing Section 629, "some may want to ask Congress to consider new options." 146 Congress need not be bothered to end the futile effort, however, since the Act provides the Commission the authority to do so itself by sunsetting the regulation. In this section, we set forth what we believe to be sound economic, legal, and evidentiary arguments to support a sunset of Section 629 under the relevant statutory provisions. First, we outline the parameters of Section 629 , and show that the ability to invoke the sunset provision will hinge on how the Commission defines "fully competitive." Given that Congress never provides a definition of "fully competitive," we next propose a definition that is flexible, economically sound, suitable to the industry, and relevant for evaluating the removal of regulation. In particular, we recommend the use of an "effectively competitive" or "workably competitive" standard. Finally, we apply this definition and find that there is a plausible legal and evidentiary case for sunset.

\section{A. Statutory Background}

Section 629(a) of the Act directs the FCC to "adopt regulations . . . to assure

143 Commercial Availability III, supra note 3, at 14,709 (statement of Comm'r Copps).

144 See Comments of Nat'l Cable and Telecomm. Ass'n, supra note 123, at 33-43; In re Video Device Competition, Implementation of Section 304 of the Telecommunications Act of 1996, Commercial Availability of Navigation Devices, Compatibility Between Cable Systems and Consumer Electronics Equipment, Joint Reply Comments of Program Networks, M.B. Docket No. 10-91, CS Docket No. 97-80, PP Docket No. 00-67, at 2-6 (Aug. 12,2010 ), available at $\mathrm{http}: / /$ commons.org/UT5w2y.

${ }_{145}$ AllVid NOI, supra note 2, at 4299 (statement of Comm'r McDowell).

146 Commercial Availability III, supra note 3, at 14,711 (statement of Comm'r McDowell). 
the commercial availability, to consumers of multichannel video programming .. . of converter boxes, interactive communications equipment, and other equipment used by consumers to access multichannel video programming . . . from manufacturers, retailers, and other vendors not affiliated with any multichannel video programming distributor." ${ }^{147}$ Under Section 629(e), the Commission may sunset these regulatory interventions upon making the following determinations: "the market for the multichannel video programming distributors is fully competitive; the market for converter boxes, and interactive communications equipment, used in conjunction with that service is fully competitive; and elimination of the regulations would promote competition and the public interest." 148 Plainly, sunset hinges largely on the definition of "fully competitive" under Sections 629(e)(1) and (2), but the Act provides no formal definition of the term. ${ }^{149}$ Nor is "fully competitive" a term of art in Economic science. While the Commission has issued some preliminary dicta on how it might define the relevant product and geographic markets for purposes of a potential Section 629 (e) petition, ${ }^{150}$ it too has shied away from providing a definition of "fully competitive." 151 Given this lack of guidance and precedent, the Commission has the flexibility to establish the parameters of the term "fully competitive" to evaluate any petition for sunset; and the Commission's parameters would be given strong judicial deference under the Chevron doctrine..$^{152}$ In our view, the agency's definition of "fully competitive" should be economically legitimate, reflect the economic realities of the communications business, and correspond to the statutory objective of assessing the value of economic regulation. We provide such a definition in the next section.

An analysis of the current state of competition under Sections 629(e)(1) and (2) is not the sole consideration for sunset, however. Section 629(e)(3), which focuses on the affirmative promotion of competition and the broader public interest, clearly requires the agency to consider the burden of regulation on economic outcomes. ${ }^{153}$ Indeed, Congress recognized the potential that FCC regulations under Section 629 could have "the effect of freezing or chilling the development of new technologies and services"154 or, just as importantly, per-

14747 U.S.C. $\$ 549$ (a).

14847 U.S.C. $\$ 549(\mathrm{e})$.

149 See 47 U.S.C. $\$ 549$ (a) (stating that regulations will "cease to apply when the Commission" determines there is fully competitive behavior) (emphasis added).

150 Commercial Availability I, supra note 13, \111 ("The Commission has stated that the relevant geographic market for assessing MVPD competition is local and its extent can be defined by the overlap of the 'footprints' of the various service providers").

${ }_{151}$ Id. ๆT 109-113 aff'd, Gen. Instrument Corp. v. FCC, 213 F.3d 724 (D.C. Cir. 2000).

152 See generally, Chevron, U.S.A., Inc. v. Natural Res. Def. Council, 467 U.S. 837 (1984).

15347 U.S.C. $\$ 549$ (e).

154 See H.R. REP. No. 104-458, at 180-81 (1996) (Conf. Rep.), reprinted in 1996 
haps be contrary to the public interest for other reasons. ${ }^{155}$ Given that the stated purpose of the 1996 Act was to reduce regulation whenever possible, ${ }^{156}$ Section $629(\mathrm{e})(3)$ provides the opportunity to sunset a regulatory effort with little hope of a positive net social return.

The Commission has not been silent on the statutory requirements for a sunset of Section 629. In its 1998 Navigation Devices Order, the agency addressed the issue. Most of the discussion is non-committal and centers on market definition. ${ }^{157}$ In that regard, the Commission defines "MPVD services" as the relevant product market for purposes of $629(\mathrm{e})(1)^{158}$ and "any navigation devices subject to Section 629" as the relevant product market for navigation devices. ${ }^{159}$ This choice of market directly coincides with the statutory setup, and is important in some respects (as discussed below). On geographic market definition, however, the statute is silent, and the Commission has not made a formal determination, but has discussed both narrow and wide market boundaries. ${ }^{100}$

The agency has made two other findings of note. First, while the Commission did not require satellite providers to comply with the CableCARD integration ban, the Commission concluded that DBS was not wholly exempt from the Section 629 mandate. ${ }^{161}$ Indeed, the agency intends for satellite providers to

U.S.C.C.A.N. 10.

iss See id. (For example, the Commission is required to be "cognizan[t] of the current state of the marketplace and consider the results of private standards setting activities" when promulgating regulation).

156 The preamble of the Telecommunications Act of 1996 directed the FCC to adhere to a "pro-competitive, deregulatory national policy framework." See, S. REP. No. 104-230, at 113 (1996) (Conf. Rep.).

157 Commercial Availability I, supra note 13, 1110 ("a relevant product market and a relevant geographic market must be determined and analyzed").

158 Id. (noting that "a relevant product market and a relevant geographic market must be determined and analyzed and that "[f]or purposes of Section 629(e), the market for MVPD programming services is an appropriate product market because the broader market definition encompasses the full range of MVPD services available to consumers").

159 Id. If 111 ("With respect to the market for equipment, we conclude that any navigation device subject to Section 629 shall constitute the appropriate equipment market for Section 629(e) purposes").

160 See discussion infra n. 151; see also Commercial Availability I, supra note 13, 1111 ("The Commission has stated that the relevant geographic market for assessing MVPD competition is local and its extent can be defined by the overlap of the 'footprints' of the various service providers. We believe that local geographic markets, akin to Nielsen's 'areas of dominant influence,' or Standard Metropolitan Statistical Areas, as determined by the Office of Management and Budget, may be an appropriate geographic market definition").

161 Commercial Availability I, supra note 13, 112 ("[W]e cannot conclude that the rules in their entirety should never be applied by virtue of the 'sunset' criteria . . . Congress did not exclude DBS from the reach of Section 629, even though the competitive state of DBS services was known at the time of the enactment of the 1996 Act."). 
participate in its AllVid scheme. ${ }^{162}$ Consequently, by the market definition discussion above, the equipment for satellite providers is part of the product market for navigation devices. ${ }^{163}$ Second, the agency does not reject the statutory "effectively competitive" standard, as defined in Section 623(1), as a useful analogy for Section 629(e)'s notion of "fully competitive." below, a definition of "effective competition" is a much more realistic standard than "perfect competition," particularly in light of how the FCC has implemented the "effective competition" standard. ${ }^{165}$

\section{B. How to Define "Fully Competitive"?}

As noted above, the 1996 Act provides no direct statutory definition of "fully competitive" in the context of Section 629(e). Implementing the section, therefore, requires the agency to assign meaning to the term. In this section, we explore two possible definitions. At the extreme, the term "fully competitive" could be associated with the textbook notion of "perfect competition." As we have explained in prior research and do so again here, this definition is entirely inappropriate for communications markets. ${ }^{166}$ Perfect competition is a Nirvana-a theoretical perfection no real world market can attain. More sensibly, we turn to the economic concept of "workably competitive" or "effectively

162 AllVid NOI, supra note $2, \boldsymbol{I} 1$.

$163 \mathrm{Id}$. at 4275 , n.2 (defining a set-top video device, also known as a "smart video device," as a product that is capable of navigating the universe of video content traditionally found in cable or satellite boxes) (emphasis added).

164 Commercial Availability I, supra note 13, \113.

165 The effective competition standard likely would be satisfied under most geographic market definitions given the ubiquitous presence of satellite video and its one-third share of the national market (exceeding the 15 percent required share). In the 2009 Report on Cable Industry Prices, 31.65 percent of subscribers are in communities that have applied for and received designation as "Effectively Competitive" markets. See In re Implementation of Section 3 of the Cable Television Consumer Protection and Competition Act of 1992, Statistical Report on Average Rates for Basic Service, Cable Reprogramming Service, and Equipment, Report on Cable Industry Prices, 26 F.C.C.R. 1769, 1786 (Feb. 14, 2011 ) (Attachment 1) [hereinafter 2011 Report on Cable Industry Prices]. This figure likely understates the present share for a number of reasons. First, this figure is from the 2009 survey, and this share is nearly double that from the last report in 2008 (18.1 percent). In re Implementation of Section 3 of the Cable Television Consumer Protection and Competition Act of 1992, Statistical Report on Average Rates for Basic Service, Cable Programming Service, and Equipment, Report on Cable Industry Prices, 24 F.C.C.R. 259, 299 (Jan. 15, 2009) (Attachment 1-b). Second, in many cases, franchise authorities were not certified to regulate cable rates, so an "Effectively Competitive" determination provides no benefits to the cable system. Third, in some cases, the legal costs and the expense of obtaining highly local data do not justify a petition.

166 See George S. Ford \& Lawrence J. Spiwak, The Impossible Dream: Forbearance After the Phoenix Order, Phoenix Center for Advanced Legal \& EConomic Public Policy Studies No. 10-08, Dec. 2010, at 8, available at http://commens.org/KQVys8. 
competitive" to give meaning to the term "fully competitive." This approach is consistent with earlier Commission findings on the sunset provision of Section $629(\mathrm{e}){ }^{167}$ Relying on these more practical concepts of competition, we are able to construct a definition of fully competitive that is economically legitimate, reflects the economic realities of the communications business, and corresponds to the statutory objective of assessing the social value of economic regulation.

\section{1. "Fully Competitive" Should Not Be Defined as "Perfectly Competitive"}

It is not uncommon for the term "fully competitive" to be linked to the textbook notion of "perfectly competitive," at least loosely. ${ }^{168}$ In the context of Section 629(e), this association would be a mistake. With perfect competition, there are large numbers of perfectly-informed buyers and sellers free to enter and exit the market at will, all engaged in transactions for a single, homogeneous product in a centralized market. ${ }^{169}$ The long-run equilibrium in such a setting has price equal to marginal cost and all firms, each identical to the others, earn zero economic profit as a consequence of the free entry and exit condition. ${ }^{170}$ Perfect competition is a useful theoretical benchmark for a frictionless economy. ${ }^{171}$ It is not, however, a useful benchmark for expected performance in the communications industry. Moreover, the static outcomes of the model of perfect competition ignore entirely the costs and benefits of regulation. ${ }^{172}$ Sunset, and even forbearance more generally, addresses the need for regulation, with full recognition that regulation may affect market outcomes in undesirable

167 Commercial Availability I, supra note 13, I 3 (stating that "certain parameters are necessary to ensure the movement of navigation devices toward a fully competitive market").

168 Colin Robinson, COMPETITION AND Regulation In Utility MaRkets 135 (2003) ("The traditional textbook model of perfect competition generated a fully competitive outcome."); MARY C. BRINTON \& VICTOR NEE, THE NEW INSTITUTIONALISM IN SOCIOLOGY 155 (1998); Milton Friedman \& SteVen G. MedemA, Price TheORY 70-4 (2007). For a historical review of the concepts of competition, see, e.g., George J. Stigler, Perfect Competition, Historically Contemplated, 65 J. POLITICAL ECON. 1, 1-17 (1957).

169 ROBERT B. EKELUND JR. \& ROBERT D. TOllision, ECONOMics 206 (4th ed. 1994).

170 Id.

171 Id. at 206, 208.

172 See e.g., Win Whittaker, A Price-Level (Incentive) Regulation Proposal for Oil Pipelines, 46 OKLA. L. REV. 415, 425 (1993) (quoting a book on regulation which points out that the real costs of regulation "go far beyond the consequences of regulation for the cost of doing business. Rather they include the impacts on domestic and international competition, the impacts on capacity decisions, and the consequences for long-term industrial strategies. In many industries that compete on bases other than cost, such as service, variety, or product reliability, and undue focus on costs can miss much that is important to competitive impact. Similarly, whatever value benefit/cost analysis might have as a basis for regulatory decision making, it is inherently incomplete."). 
ways. Section $629(\mathrm{e})(3)$, for example, expressly recognizes that the regulation may impede competition or may conflict with the public interest in other ways. ${ }^{173}$ Regulation is costly; any meaningful definition of competition used in the context of a sunset or forbearance provision must account for that fact. ${ }^{174}$

The equilibrium outcome of primary interest from the model of perfect competition of that price is equal to the marginal cost of production. Given the high fixed and sunk costs necessary for the production of communications services, ${ }^{175}$ this outcome is entirely infeasible in communications markets. Price must exceed marginal cost by a sufficient amount to cover the fixed costs of production. ${ }^{176}$ The Commission understands the supply-side conditions. In the National Broadband Plan, for example, the agency observed, "building broadband networks-especially wireline-requires large fixed and sunk investments." 177 As a result, the agency concluded, "the industry will probably always have a relatively small number of facilities-based competitors," but also that "the lack of a large number of . . . providers does not necessarily mean competition among broadband providers is inadequate." 178

Indeed, perfect competition is a dubious benchmark, and this fact is well established in literature on telecommunications regulation. In the TELECOMMUNICATIONS REGULATION HANDBOOK, for example, a discussion of costs and pricing notes that:

[M] arginal cost is below average costs, and setting a regulated price equal to marginal cost will not allow the operator to recoup all of its costs. In order for the operator not to lose money and go out of business, the regulator had to set at least some prices above marginal cost. ${ }^{179}$

173 Congress was cognizant that regulation "could have the effect of freezing or chilling the development of new technologies and services" and directed the Commission to take into consideration different factors such as the current state of the marketplace. See H.R. REP. No. 104-458 (1996) (Conf. Rep.), reprinted in 1996 U.S.C.C.A.N. 10.

174 See e.g., William P. Rogerson, The Regulation of Broadband Telecommunications, the Principle of Regulating Narrowly Defined Input Bottlenecks, and Incentives for Investment and Innovation, 2000 U. CHI. LEGAL F. 119, 138 (2000) (asserting that "any regulation is costly to implement and likely to create various distortions that would not occur if it were possible for competition to operate freely and perfectly"); Anita I. Anand, Combating Terrorist Financing: Is Canada's Legal Regime Effective?, 61 U. TORONTO L.J. 59,60 (2011) (regulation is "costly, and ineffective regulation imposes unnecessary costs on the private and public sectors"); see also discussion infra Figure 1.

175 NATIONAL BROADBAND PLAN, supra note 3, at 36.

176 See J. Gregory Sidak, The Failure of Good Intentions: The WorldCom Fraud and the Collapse of American Telecommunications After Deregulation, 20 YALE J. ON REG. 207, 250 (2003).

177 NATIONAL BroadBand PLAN, supra note 3, at 36.

178 Id. at 36-37.

179 Hank IntVen, Jeremy Oliver \& Edgardo Sepulvida, Telecommunications RegULATION HANDBOOK B-17 (2000); see also ClEMENT G. KROUSE, THEORY OF INDUSTRIAL ECONOMICS 55 (1990) ("In a homogeneous goods industry the presence of increasing returns in production creates difficulties in using perfect competition as a benchmark for social 
Plainly, the marginal cost outcome of the model of perfect competition is incompatible with markets with high fixed and sunk costs of production. Put another way, marginal cost pricing does not create equilibrium in communications markets. As noted by Jean Tirole in reference to duopolistic competition, "both firms charging the competitive prices, [price equals marginal cost], is generally not an equilibrium." never compatible with the equilibrium in communications marketsincluding cable television-it seems clear that perfect competition is not a useful benchmark.

This fact is not lost on the Commission. Indeed, there are many instances where the FCC itself devises policy in full recognition of the prevalence of fixed and sunk costs and their implications for pricing. ${ }^{181}$ For example, when the agency set a price for certain types of payphone calls, it concluded:

Because payphones have significant fixed costs that must be recovered, the price for each type of payphone call must exceed the marginal cost of the call if the payphone is to earn a normal rate of return. Stated another way, if every call is priced at the marginal cost of that call, the payphone would be unprofitable, because it would fail to recover the predominant fixed costs of providing the payphone. ${ }^{182}$

Likewise, in its 2008 SATELlITE COMPETITION REPORT, the agency observed:

[M]etrics of the unit price-cost margin . . . are difficult to interpret as indicators of market power and the extent of competitive rivalry in industries where firms, such as satellite carriers, utilize technologies with large fixed costs and substantial economies of scale. ... Pricing output at marginal cost ... is therefore unprofitable for satellite firms, since such pricing will produce losses equal to the fixed costs of production. ${ }^{183}$

Even former FCC Chairman Reed Hundt observed:

In an industry with large sunk costs and small marginal costs, like most of the telecommunications industry, pricing that goes to marginal cost will not provide an adequate return to the investors who provide capital. Investors will be cautious about investing money upfront because ex post competition could drive prices to nonremu-

efficiency. Prices set equal to marginal cost in this case will lead to losses").

180 JeAn TIROLE, THE THEORY OF INDUSTRIAL ORGaNIZATION 214 (1988).

181 See, e.g., NATIONAL BROADBAND PLAN, supra note 3, at 47 ("economies of scale, scope and density that characterize telecommunications networks"); In re Review of Section 251 Unbundling Obligations of Incumbent Local Exchange Carriers; Implementation of the Local Competition Provisions of the Telecommunications Act of 1996; Deployment of Wireline Services Offering Advanced Telecommunications Capability, Report and Order and Order on Remand and Further Notice of Proposed Rulemaking, 18 F.C.C.R. 16978, 1 244 (Feb. 20, 2003).

182 In re Implementation of the Pay Telephone Reclassification and Compensation Provisions of the Telecommunications Act of 1996, Third Report and Order, and Order on Reconsideration of the Second Report and Order, 14 F.C.C.R. 2545, If 33 (Jan. 28, 1999) (footnotes omitted).

183 In re Second Annual Report and Analysis of Competitive Market Conditions with Respect to Domestic and International Satellite Communications Services, Second Report, 23 F.C.C.R. 15170, ๆ 90 (Oct. 14, 2008). 
nerative levels. ${ }^{184}$

Plainly, the inapplicability of the model of perfect competition in communications markets is widely accepted. In fact, the price equals marginal cost outcome could lead to a more direct legal challenge of using perfect competition as a performance benchmark. For example, viewed in the context of the traditional "just and reasonable" ratemaking standard found in Section 201, ${ }^{185}$ to define "fully competitive" as "perfectly competitive" sets a de facto benchmark standard which is "confiscatory" and outside of the "zone of reasonableness," since marginal cost pricing does not permit the recovery of all costs in communications markets characterized by high fixed and sunk costs. ${ }^{186}$

In sum, while perfect competition is a legitimate theoretical concept, its policy relevance is less clear. Perfect competition is a textbook Nirvana that fails to reflect the economic realities of the communications industry-and nearly every other industry. The static outcomes of the perfectly competitive equilibrium are wholly incompatible with the supply-side economic conditions of the communications markets. Furthermore, the static outcomes of perfect competition provide no insight into the statutory objective of assessing the value of economic regulation. A narrow focus on price-cost margins says nothing about the costs of regulation, and such costs should be contemplated by statute.

Moreover, the statute itself recognizes that the regulation may impede competition and, therefore, a refusal to sunset the provisions due to a lack of competitive perfection conflicts with congressional intent. ${ }^{187}$ As discussed below, economic research provides significant guidance on a more meaningful standard for the Commission to adopt when defining "fully competitive" under Section 629(e).

\section{2. "Fully Competitive" is Better Defined as "Effectively Competitive" or} "Workably Competitive"

Economists have long been dissatisfied with the rigid concept of perfect competition as a standard for actual market outcomes. ${ }^{188}$ Few, if any, markets

184 Reed E. Hundt \& Gregory L. Rosston, Communications Policy for 2006 and Beyond, 58 FED. COMM. L.J. 1, 6 (2006).

18547 U.S.C. $\$ 160$ (a).

186 See, e.g., Verizon v. FCC, 535 U.S. 467, 481 (2002); Farmers Union Cent. Exch. v. FERC, 734 F.2d 1486, 1502 (D.C. Cir. 1984). Nevertheless, the FCC is not always so judicious in its acknowledgement and application of economic principles. For example, in its recent Phoenix Forbearance Order, the agency establishes a marginal cost pricing standard for Section 10 forbearance-a standard that will be impossible to satisfy. See Ford \& Spiwak, The Impossible Dream, supra note 166, at 8.

187 See 47 U.S.C. \& 549(e)(1)-(3).

188 See e.g., Howard A. Shelanski, Adjusting Regulation to Competition: Toward A New 
are perfectly competitive, but this fact does not warrant widespread government intervention. As a result, economists began to develop the concept known as "workable" or "effective" competition. ${ }^{189}$ Generally, workable or effective competition implies the absence of significant monopoly power, where the adjective "significant" implies sufficient market power that would warrant the costs of attempting to reduce it through antitrust or regulatory action. ${ }^{190}$

William Shepherd provides an excellent sketch of the issue in his book, THE ECONOMICS OF INDUSTRIAL ORGANIZATION:

The basic question is how many comparable competitors are needed for effective competition: as many as 100 or $\mathbf{2 0}$ or eight, or instead as few as two? ...

What gives an effective degree of competition has been debated with increasing rigor since Adam Smith's Wealth of Nations in $1776 . .$.

After 1870 , neoclassical economists began to carry the concept of competition to its pure, "atomistic" extreme, deriving the precise efficiency results found in beginning economics texts .... Competition came to be defined as an equilibrium result enforced by the relentless pressures of numberless tiny competitors.

Practical-minded observers have long disapproved of such models as too abstract and extreme. A strong degree of rivalry among several firms ... can give the same general degree of efficiency, while also providing for rapid innovation. This realistic view of the competitive process among a few rivals is often said to conflict with the neoclassical analysis of equilibrium among numberless firms in atomistic markets. ...

Yet no such conflict over the true nature of competition really needs to exist. ... [T] he aim has been only to have intense competition, so that firms are under strong mutual pressure....

One cannot just count firms in judging the degree of competition....

At times, even if there are only two competitors, their rivalry may be intense. Though one of the two firms may get the upper hand for a while in a market, the other may soon fight back and equalize its share of the market and profits. Such a continuing rugged rivalry may stir great efforts from the firms and force prices down close to the levels of their costs. Therefore, effective competition is possible even when there are as few as two or several firms.

...[C]ompetition is a process that can be effective when it is less comprehensive than in the ideal, pure case. ${ }^{191}$

Shepherd's observation that "even if there are only two competitors, their rivalry may be intense" and that "one cannot just count firms in judging the degree of competition" is exceedingly relevant for communications markets

Model for U.S. Telecommunications Policy, 24 YALE J. ON REG. 55, 81 (2007) (noting that perfect competition is the wrong standard for market performance in high-fixed-cost industries and that some margin above incremental, variable cost is necessary); FrANK H. KNIGHT, RISK, UNCERTAINTY, AND ProfIT $\S$ I.I.24 (1921), available at $\mathrm{http} / / /$ commens.org/V8jT4O (asserting that "the problem of profit is one way of looking at the problem of the contrast between perfect competition and actual competition.").

189 David L. Kaserman \& John W. Mayo, Government and Business: The EConomICS OF ANTITRUST AND REGULATION 100-01 (1995).

190 Id.

191 WiLliam G. SHEPHERD, ThE ECONOMICS OF INDUSTRIAL ORgANIZATION 9-10 (1985). 
where the supply-side characteristics often lead to relatively concentrated equilibriums. ${ }^{192}$ Concentration, however, need not imply a lack of rivalry. In the National Broadband Plan, the Commission concurs, concluding, as noted above, that "the lack of a large number of . . providers does not necessarily mean competition among broadband providers is inadequate."193

Economist Jesse Markham provides an even more useful conceptualization of the issue in the AMERICAN ECONOMIC REVIEW:

A possible alternative approach to the concept of workable competition may be one which shifts the emphasis from a set of specific structural characteristics to an appraisal of a particular industry's over-all performance against the background of possible remedial action. Definitions of workable competition shaped along these lines might accept as a first approximation some such principle as the following: An industry may be judged to be workably competitive when, after the structural characteristics of its market and the dynamic forces that shaped them have been thoroughly examined, there is no clearly indicated change that can be effected through public policy measures that would result in greater social gains than social losses. Tautological through [sic] this type of definition might be, it at least avoids the pitfall of listing specific market conditions that can have very limited general applicability. Also, it would ascribe paramount importance to that which should be uppermost in the minds of those who formulate public policy - the possibility of prescribing appropriate remedial action. For, unless the concept of workable competition is to be an instrument of public policy, there is little reason for differentiating between workable and pure competition. But to frame definitions for public policy purposes without taking cognizance of the different structural features among industries and within the same industry at specific stages of development, and without recognizing at the outset the political and economic limitations placed upon policymaking authorities, would be to ignore the primary purpose of such definitions, i.e., to indicate wherein an industry does not operate in the public's interest and what appropriate remedial action is possible. ${ }^{194}$

Here we have a very sensible approach to assessing competition in the context of a sunset provision (or forbearance more generally). Markham recommends the joint assessment of "a particular industry's over-all performance," which includes not only the observed market outcomes but also the efficacy of "possible remedial action." 195 In other words, while we may observe prices in excess of marginal cost, and perhaps by a sizeable amount, this outcome cannot be viewed independent of the policymaker's ability to do something useful about it. Put another way, a claim of a "market failure" is insufficient to warrant regulation or to postpone forbearance from regulation. Inseparable from

192 See id. at 10.

193 National Broadband Plan, supra note 3, at 37; see also George.S. Ford, Thomas M. Koutsky \& Lawrence J. Spiwak, Competition After Unbundling: Entry, Industry Structure, and Convergence, 59 FED. COMM L.J. 331, 346-51 (2007) ("Empirical and experimental research has shown that there is substantial variation in the relationship between the number of firms (or industry concentration) and prices/profits across industries and over time.").

194 Jesse W. Markham, An Alternative Approach to the Concept of Workable Competition, 40 AM. ECON. R. 349, 361 (1950).

195 Id 
the market outcome is whether some change "can be effected through public policy measures that would result in greater social gains than social losses."196

This notion of workable competition can be illustrated using a simple graph. In Figure 1, we have a demand curve for a good, labeled D. There are three prices: the monopoly price $\left(\mathrm{P}_{\mathrm{M}}\right)$, the duopoly price $\left(\mathrm{P}_{\mathrm{D}}\right)$, and the regulated price $\left(\mathrm{P}_{\mathrm{R}}\right)$, with respective quantities $\mathrm{Q} i$. Assume marginal cost is zero (MC) and regulation imposes a fixed administrative burden set equal to the rectangular area $\mathbf{R}$ in the figure. ${ }^{197}$

\section{Figure 2. Regulation and Welfare}

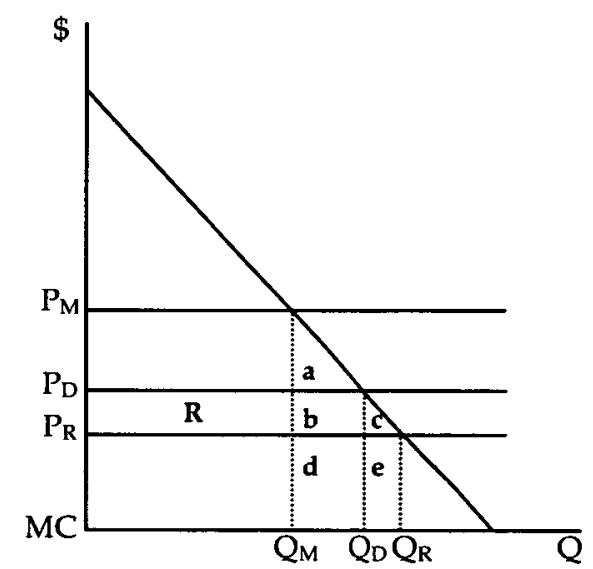

If the choice is between monopoly and regulation (price-quantity combinations $P_{M}, Q_{M}$ and $P_{R}, Q_{R}$ ), then the welfare gains are equal to the abcde less costs $\mathbf{R}$, which is clearly positive. Alternately, if the choice is between duopoly and regulation (price-quantity combinations $P_{D}, Q_{D}$ and $P_{R}, Q_{R}$ ), the welfare gain is only ce which is less than $\mathbf{R}$. Thus, on economic welfare grounds (at least in the partial equilibrium analysis), regulation is too costly in the case of duopoly, even though regulation increases welfare in the case of monopoly. ${ }^{198}$ Notably, the implementation of cable rate regulation was based on the rule

196 Id.

197 The choice of $\mathbf{R}$ is illustrative only and has nothing to do with the prices or quantities. The costs of regulation could take many forms other than a fixed administrative cost. Also, the cost of implementing regulation may be much higher in a duopolistic setting than under monopoly conditions.

198 See T. Randolph Beard, George S. Ford, Lawrence J. Spiwak \& Michael Stern, $A$ Policy Framework for Spectrum Allocation in Mobile Communications, 63 FED. COMM. L.J. 639, 653 (2011), available at http://commcns.org/XhrXyT. 
$P_{R}=P_{D}$ because rate reductions were based on the competitive differential. ${ }^{199}$ In all cases, prices are well in excess of marginal cost, illustrating that the model of perfect competition offers little guidance on the question of the social value of regulation.

Interestingly, a formal definition of "fully competitive" is provided in the Encarta Dictionary. Encarta defines a fully competitive service as "a service for which market forces are sufficiently strong to eliminate the need for government regulation." ${ }^{200}$ This general definition is useful in that, as with Markham, competition need not be textbook perfect to be fully competitive, just adequate enough to eliminate the likelihood of welfare-improving remedial action by either antitrust or regulation. ${ }^{201}$ This definition is consistent with the logic underlying the "effectively competitive" standard in Section 623(1).

This notion of workably or effectively competitive is supported directly by the 1996 Act with regard to cable television markets. Specifically, Congress permitted the elimination of rate regulation for basic tier MVPD programming in markets that are subject to "effective competition." fines "effective competition" as:

A. fewer than 30 percent of the households in the franchise area subscribe to the cable service of a cable system;

B. the franchise area is . . served by at least two unaffiliated multichannel video programming distributors each of which offers comparable video programming to at least 50 percent of the households in the franchise area; and $\ldots$ the number of households subscribing to programming services offered by multichannel video programming distributors other than the largest multichannel video programming distributor exceeds 15 percent of the households in the franchise area;

C. a multichannel video programming distributor operated by the franchising authority for that franchise area offers video programming to at least 50 percent of the households in that franchise area; or

D. a local exchange carrier or its affiliate (or any multichannel video programming distributor using the facilities of such carrier or its affiliate) offers video programming services directly to subscribers by any means (other than direct-to-home satellite services) in the franchise area of an unaffiliated cable operator which is providing cable service in that franchise area, but only

199 See Thomas Hazlett \& Matthew Spitzer, Public Policy Toward Cable TeleviSION: THE ECONOMICS OF RATE CONTROLS 26-29 (MIT Press 1997) (discussing pricing effects in different markets).

200 ENCARTA WORLD ENGLISH Dictionary (2009); see also 2.3 Regulation in a Fully Competitive Environment, ICT REGULATION TOOLKIT, http://commcns.org/11C900E (last visited Nov. 10, 2012) ("In a fully competitive environment, there is a more limited need for regulation.").

201 Implicit is that market forces are sufficient to protect consumers and ensure just and reasonable rates. Markham, supra note 193, at 361 .

202 See 47 U.S.C. $\S 543(\mathrm{a})(2)$ ("[1]f the Commission finds that a cable system is subject to effective competition, the rates for the provision of cable service by such system shall not be subject to regulation by the Commission or by a State or franchising authority ...."). 
if the video programming services so offered in that area are comparable to the video programming services provided by the unaffiliated cable operator in that area. ${ }^{203}$

In subpart (A), deregulation is permitted when the cable system has a very low penetration. ${ }^{204}$ Deregulation in such cases has two sensible justifications. First, the benefits of regulation in low penetration markets may not be sufficient to offset the administrative costs of rate controls. The logic follows directly from Figure 1 above. Second, a low penetration may be indicative of competition from other sources. ${ }^{205}$ The remaining subparts define effective competition - that is, competition sufficient to warrant the removal of all rate regulations - in its most stringent case as the presence of a single competitor offering service to at least half the market. ${ }^{206}$ Effective competition, therefore, is defined by Congress as the presence of, essentially, half a competitor as the most stringent test. In subpart (D), there is no market overlap requirement. ${ }^{207}$ Subpart (B) is the most stringent standard, requiring both a 50-percent overlap and 15-percent penetration by the rival. ${ }^{208}$ The threshold Hirschman Herfindahl Index ("HHI") for effective competition (and deregulation) under this section is $7,450 .{ }^{209}$

The Commission's actual implementation of the "effective competition" standard also indicates that perfect competition is unsuitable. In its review of basic cable deregulation in Montgomery County, Maryland, the Media Bureau concluded:

There is no statutory basis to delay basic rate deregulation in a franchise area until the arrival of perfect competition there and the resolution of all issues between a cable operator and a franchise authority to the latter's satisfaction. Indeed, Section 623(b)(1) of the Act, which the County invokes, sets the standard for basic cable rates not at perfect competition, but at the level that would be charged if there were effective compe-

20347 U.S.C. $\$ 543(1)(1)(A)-(D)$.

20447 U.S.C. $\$ 543(1)(1)($ A).

205 See 2011 Report on Cable Industry Prices, supra note 165, 1805 n.31 (suggesting that low market penetration may have resulted from the presence of a second operator in the community).

20647 U.S.C. $\$ 543(\mathrm{l})(1)(\mathrm{B})-(\mathrm{D})$.

20747 U.S.C. $\& 543$ (I)(1)(D). With regard to LEC entry, it is the threat that matters. See In re Implementation of Cable Act Reform Provisions of the Telecommunications Act of 1996, Report and Order, 14 F.C.C.R. 5296, I 11 (Mar. 25, 1999) ("[T]he Cable Services Bureau has found that a LEC's presence can have a competitive impact on a cable operator before the LEC finishes installing its plant or rolling out its service. We see no reason from the record before us not to continue applying the LEC test in this way when the likelihood of impending competition throughout a substantial part of the incumbent cable operator's service area is established, the competitive service is commercially available, and potential subscribers in the franchise area served by the incumbent are reasonably aware that the service is either actually available to them or will be available within a reasonable time.").

20847 U.S.C. $\$ 543(1)(1)(B)(i i)$.

209 The calculation is $85^{2}+15^{2}$. See Dep'T OF Justice \& FTC, Horizontal Merger GUIDELINES 18-19 (2010), available at http://commens.org/SQDglP. 


\section{tition. $^{210}$}

Plainly, the Commission rejects the perfect competition standard when approving deregulation of cable television services.

Notably, we do not necessarily advocate for or reject the formal adoption of the provisions of Section 623(1)(1) as a test to see whether Section 629(e) is satisfied. Nevertheless, Section 623 is important in that Congress deliberately established a standard of effective competition that is far less than the textbook notion of "perfect competition," and codified the idea that even a little competition eliminates the need for regulation. Furthermore, as discussed above, in its Navigation Devices Order, the Commission acknowledged the "effectively competitive" standard is a suitable benchmark for a "fully competitive" MVPD marketplace, though perhaps applying the overlap and penetration thresholds to a larger geographic area than just a franchise market. ${ }^{211}$

In light of this discussion, we propose to define fully competitive for purposes of Section 629(e) as a "condition where market forces are sufficiently strong to eliminate the need for government regulation." ${ }^{212}$ As noted above, this definition has many advantages. First, it is drawn from the economic literature, and thus has academic legitimacy. ${ }^{213}$ Second, it is consistent with the underlying economic realities of the communications industry, where marginal cost pricing is infeasible. ${ }^{214}$ Third, it is a very good match for the problem at hand, where the sunset provision of Section 629(e) involves setting aside regulation, and explicitly requires the agency to consider the costs of intervention on both competition and the public interest. Fourth, the definition requires that there be some force operating on price sufficient to permit the removal of regulation. ${ }^{215}$ Consistent with the "effective competition" standard in Section 623(1), that force could be the presence of a competitor serving some portion of the market and exerting downward pressure on prices or affecting quality or some other mode of rivalry. Fifth, by including the "need for government regulation" in the definition, the parameters of "fully competitive" can vary across issues, providing flexibility to the agency. Since the cost and benefits of regulation vary across interventions, the threshold level of "market forces" sufficient to make regulation unnecessary will not be uniform across all regulatory inter-

210 In re Comcast Cable Communications, LLC, on behalf of its subsidiaries and affiliates; Petition for Determination of Effective Competition in Two Communities in Maryland, Memorandum Opinion and Order, 25 F.C.C.R. 13340, I 12 (Sept. 21, 2010) (footnotes omitted).

211 See infra Section III; Commercial Availability I, supra note 13, \64.

212 Implicit is that market forces are sufficient to protect consumers and ensure just and reasonable rates.

213 See KASERMAN \& MAYO, supra note 189, at 100-01.

214 See Ford \& Spiwak, The Impossible Dream, supra note 166, at 9.

215 Regulation may be too costly even in the presence of monopoly. 
ventions. ${ }^{216}$ Therefore, a finding of "fully competitive" for Section 629(e) need not translate to a finding of "fully competitive" in any other instance.

\section{Satisfying the Statute}

In order to sunset Section 629(a), Section 629(e) requires the Commission to make, at a minimum, a plausible argument that the market for multichannel video programming and the market for converter boxes and interactive equipment are "fully competitive." 217 As noted above, for purposes of Section 629(e), we define "fully competitive" as a situation where market forces are sufficiently strong to eliminate the need for government regulation. We now discuss each determination in turn.

\section{The Market for Multichannel Video Programming is "Fully Competitive" for Purposes of 629(e)(1)}

Given our definition of "fully competitive," the Commission could make several plausible arguments that the first prong of Section 629(e) is satisfied. In the Navigation Devices Order, the Commission did not finalize its position on a geographic market definition for MVPD services. ${ }^{218}$ Yet, regardless of whether we assume for purposes of Section 629(e)(1) that the market for multichannel video programming is local or national, ${ }^{219}$ there are at least two competitors in every market—satellite television (DirecTV and Dish) is essentially ubiquitous and is a very real and significant competitor in the market. ${ }^{220}$ The most recent Video Competition Report, which draws conclusions based on 2006 data, observes:

We find that almost all consumers are able to obtain programming through over-theair broadcast television, a cable service, and at least two DBS providers. In some areas, consumers also may have access to video programming delivered by emerging technologies, such as digital broadcast spectrum, fiber-to-the-home facilities, or webbased Internet video. ${ }^{221}$

Similarly, in the National Broadband Plan, the agency observed, "four out

216 In Figure 1, different conclusions can be drawn by altering the size of $\mathbf{R}$.

217 See 47 U.S.C. \$ 549(a), (e).

218 Commercial Availability I, supra note 13, $\{111$.

219 Id. ("[T] he relevant geographic market for assessing MVPD competition is local and its extent can be defined by the overlap of the 'footprints' of the various service providers.").

${ }^{220}$ See In re Time Warner Cable Inc.; Time Warner Entertainment-Advance/Newhouse Partnership; Petition for Determination of Effective Competition in Four Massachusetts Communities, 23 F.C.C.R. 6441, $\mid$ (Apr. 14, 2008).

221 See In re Annual Assessment of the Status of Competition in the Market for the Delivery of Video Programming, Thirteenth Annual Report, 24 F.C.C.R. 542, I 4 (Nov. 27, 2007) [hereinafter Thirteenth Annual Report]. 
of the top 10 MVPDs are not cable companies and represent $41 \%$ of MVPD subscribers." ${ }^{222}$ Indeed, current conditions stand in stark contrast to when the FCC first issued its Navigation Devices Order back in 1998 where DBS was "still a relatively new entrant in the MVPD market . . .".223 As such, customers have multiple choices of providers, and the number of choices is rising with the actual entry of telephone companies in many markets and over-the-top video services wherever broadband is available. ${ }^{224}$

While non-committal in defining local geographic markets in the Navigation Devices Order, the Commission suggested that Nielsen's Areas of Dominant Influence, or Standard Metropolitan Statistical Areas could provide assistance in defining "appropriate geographic market definition[s]."225 These geographic areas are very similar to Nielsen's Designated Market Areas ("DMAs"), for which we have competitive information. ${ }^{226}$ Recent evidence indicates that noncable video delivery systems (or "alternative delivery systems" or "ADSs") account for at least 15 percent market share of television households in 203 of the largest 210 DMAs, satisfying the "effectively competitive" standard of Section 623(1) for almost every U.S. household. ${ }^{227}$

A "fully competitive" finding in the MVPD market under Section 629(e) should not be problematic before a reviewing court. For example, in striking down the Commission's Cable Ownership Cap Rule, the D.C. Circuit found, among other things, that DBS companies alone now serve approximately 33 percent of all subscribers (satisfying Section $623(1)(1)(B)$ if viewed at the national level), ${ }^{228}$ and DirecTV and Dish Network each serve more customers than any cable company with the exception of Comcast. ${ }^{229}$ Indeed, the court found that:

[T] ] record is replete with evidence of ever increasing competition among video providers: Satellite and fiber optic video providers have entered the market and grown in market share since the Congress passed the 1992 Act, and particularly in recent years. Cable operators, therefore, no longer have the bottleneck power over pro-

222 National Broadband Plan, supra note 3, at 51.

223 Commercial Availability I, supra note 13, \$1 112.

$224 C f$. National BRoAdBand Plan, supra note 3, at 51, $67 \mathrm{n} .116$ (noting entry of Verizon Communications and AT\&T to the MVPD market).

225 Commercial Availability I, supra note 13, \111.

226 Geographic Definitions, MARKETING SYSTEMS GrouP, http://commcns.org/Xhsgd4 (last visited Nov. 10, 2012) (defining DMAs as "a geographic area that represents individual television markets as defined by Nielsen Media Research. DMA's are typically defined by county and the market definitions are updated each fall by [Nielsen].").

${ }_{227} A D S$, OTA, and Wired-Cable Penetration by DMA, TELEVISION ADVERTISING BuREAU, http://commcns.org/Xhsn8o (last visited Nov. 10, 2012). These markets include almost all United States households. Local Television Market Universe Estimates, NIELSEN COMPANY (Jan. 1, 2011), available at http://commens.org/XdKOKB.

228 Comcast Corp. v. FCC, 579 F.3d 1, 6 (D.C. Cir. 2009).

229 Id. at 1,8 . 
gramming that concerned the Congress in $1992 .^{230}$

Since this sentiment was expressed before over-the-top video had become a serious contender in video distribution, it is not unreasonable to expect a willingness by the court to accept a finding of a fully competitive MVPD market.

Finally, given that Congress price deregulated cable programming above "basic tier" services in the 1996 Act, ${ }^{231}$ we can also infer that Congress deemed the market for higher tier cable services to be "fully competitive" for purposes of Section 629(e). As observed at the time by Rep. Edward Markey,

The pending legislation will deregulate the rates of most cable systems 3 years from now - in March 1999. The rationale for deregulating cable systems at that point is due largely to the success of the Cable Act of 1992 . . . [The 1992 Act] gave emerging satellite competitors and others access to cable programming, making competition viable. I am encouraged by the progress that direct broadcast satellite companies and wireless cable companies are making in signing up customers and competing against incumbent cable operators. ${ }^{232}$

Thus, Congress, in the 1996 Act, determined that the multichannel video market was "fully competitive" in the sense that market forces were sufficiently strong to eliminate the need for government regulation for cable programming services. ${ }^{233}$ Representative Markey's statement includes words like "emerging" and "progress," suggesting that the deregulation was based on the belief that competitive alternatives would succeed going forward; if this was Congress' belief, it has come to fruition. From 1995 to 2006, for example, direct broadband satellite services grew from 1.7 million to 28 million subscribers, the latter representing about 29 percent of all U.S. MVPD subscribers. ${ }^{234}$ More recent evidence indicates that DBS players control a thirty-three percent market share and "four out of the top 10 MVPDs are not cable companies and represent 41 percent of MVPD subscribers."235

230 Id

23147 U.S.C. $\$ 543($ b)

232142 CONG. REC. 1169 (1996) (statement of Rep. Ed. Markey supporting the conference report to $S .652$ ).

233 Of course, Congress did leave the basic programming tier regulated subject to a subsequent determination that a particular franchise was subject to "effective competition." Notably, the FCC has granted petitions of effective competition in over 7,000 cable systems, including many large cable systems. See 2011 Report on Cable Industry Prices, 714 . Franchising authorities have chosen not to regulate basic tier rates in numerous other systems, providing further evidence of the competitive nature of the MVPD market across the country. In re Implementation of Section 3 of the Cable Television Consumer Protection and Competition Act of 1992; Statistical Report on Average Rates for Basic Service, Cable Programming Services, and Equipment, Report on Cable Industry Prices, 12 F.C.C.R. 22,756, 1 $13 \&$ n.8.

234 Compare In re Annual Assessment of the Status of Competition in the Market for the Delivery of Video Programming, Second Annual Report, 11 F.C.C.R. 2060, I 49 (Dec. 7, 1995) (1.7 million DBS subscribers), with Thirteenth Annual Report, supra note 221, I 75 (27.97 million DBS subscribers).

235 Comcast Corp. v. FCC, 579 F.3d 1, 6 (D.C. Cir. 2009); National BroadBand Plan, 
Based on this evidence and a sensible and well-documented definition of the term "fully competitive," we believe that the Commission can make a positive determination that the market for multichannel video programming is "fully competitive" for purposes of Section 629(e). In so doing, the first-prong of the sunset provisions of Section 629(e) is satisfied.

\section{The Market for Converter Boxes and Interactive Equipment is "Fully Competitive" for Purposes of 629(e)(2)}

Again, under our standard, the market for converter boxes and interactive communications equipment used in conjunction with that service is fully competitive for purposes of Section 629(e) if there are market forces sufficiently strong to eliminate the need for government regulation. As with the first prong of Section 629(e), a finding by the FCC that the equipment market is "fully competitive" presents no difficulty. Recall that the 1998 Navigation Devices Order defined the equipment market to include any navigation devices subject to Section $629 .{ }^{236}$ Marketplace evidence reveals that there are a large number of sellers of converter equipment in such a market. Suppliers of set-top box equipment include, but are not limited to, Pace, Motorola, Cisco, Evolution Broadband, Samsung, Zoom, Panasonic, ARRIS, and Tivo. ${ }^{237}$ Further, there has never been, nor is there any proposal for, regulation of the equipment manufacturing industry. While it is true that Motorola and Cisco held a sizeable share of the set-top box market, emerging competition is substantially impacting sales by these firms. ${ }^{238}$ But, even if the two companies split the entire market, their rivalry would satisfy the 50-15 standard of $623(1)(1){ }^{239}$ Evidence of hit-and-run entry in the past suggests that the market share success of these companies may be largely due to superior efficiency and technology rather than any anticompetitive actions. ${ }^{240}$

supra note 3 , at 51 .

236 Commercial Availability I, supra note $13, \uparrow 111$.

237 Comments of Nat'l Cable and Telecomm. Ass'n, supra note 123, at 9 ("Cable operators now purchase set-top boxes from a growing number of consumer electronics manufacturers, including Pace, Motorola, Cisco, Evolution Broadband, Samsung, Panasonic, ARRIS, and TiVo.").

238 Todd Spangler, Cisco's Cable Sales Get Hammered Set-Top Sales in North America Drop 40\% Year-Over-Year, MulTICHANNEl News (Nov. 11, 2010), http://commons.org/13lw7VU; John Pletz, Motorola Mobility's Cable Set-Top Box Unit Losing Ground, CRAIN's ChI. BuSINESs (June 6, 2011), http://commons.org/YbNejz; Jeff Baumgartner, Samsung Boxes Break In at Cablevision, Light REAdING CABle (Aug. 19, 2010), http://commens.org/Vruclz.

23947 U.S.C. $\$ 543(1)(1)(B)$.

240 Baumgartner, supra note 238 . Hit-and-run entry requires low sunk entry costs, which permits firms to enter a market in pursuit of profits, and exit if profits turn out to be unavail- 
Recent evidence indicates that industry concentration in the navigation devices market is falling rapidly. ${ }^{241} \mathrm{~A}$ market survey by Infonetics Research, released in March 2011, provides market share data for the navigation devices market for the years 2008, 2009 and 2010. ${ }^{242}$ This data is summarized in Table 1. Using the market share data from this report to compute an HHI for the industry in 2008 indicates something much like duopoly, where the HHI would be 5,000 if the firms were equal sized. In 2010, alternately, the HHI had fallen significantly, to the equivalent of just over five firms. Under the $2010 \mathrm{Merger}$ Guidelines, the HHI is just above the threshold $(1,500)$ for an "unconcentrated market." ${ }^{243}$ A continued decline in industry concentration is expected, as cable operators-and consumers-further diversify their equipment supplier base. For example, TiVo entered into agreements to provide joint services with Comcast and DirecTV, and (other things constant) its market share is expected to rise as a result (subsequent to full implementation). ${ }^{244}$ In any case, the set-top market in the recent past, much less in the now distant past when the 1996 Act was written, is not the same market as today. The potential benefits from Section 629 are, consequently, much smaller, though there is little reason to suspect the costs of mandated technology standards have fallen.

able. The history of hit-and-run entry in the set-top market, by firms like Sony, could be used to suggest the converter box market is contestable, implying competitive outcomes even when only one or a few firms participate in the market. See William J. Baumol, Contestable Markets: An Uprising in the Theory of Industry Structure, 72 AM. ECON. REv. 1, 4 (1982).

241 Note, however, that concentration does not directly map to competitiveness.

242 Cable, Satellite, IPTV, and OTT Set-Top Boxes and Subscribers, Quarterly Worldwide and Regional Market Share, Size and Forecasts, 4Q10, INFONETICs RESEARCH (Mar. 16, 2011), http://commons.org/WKSZy2 (on file with CommLaw Conspectus).

243 UNITED Sta TES DeP'T OF JUSTICE \& FED. TRADE COMM'N, supra note 209, at 18-19.

244 Full integration of the services remained "in process" as of the publication of this paper. See, e.g., Eric A. Taub, Tivo and DirecTV Together Again, N.Y. TiMES (Mar. 28, 2012), http://commens.org/XGY2IR; Benny Evangelista, TiVo-Comcast service mix finally happens - 7 years later, SFGATE (Apr. 10, 6:30 PM), http://commcns.org/XGY7FY. See also TiVo and Comcast Team Up to Offer the First Retail Cable Set-Top With DVR That Delivers Linear TV, Broadband Content and Xfinity On Demand Library All From One Box Comcast to Help TiVo to Promote Solution with Retail and Marketing Support, PR-INSIDE (May 09, 2011, 2:38 PM), http://commens.org/102cgx6; Press Release, DirecTV, DIRECTV and TiVo to Launch New HD DIRECTV DVR with TiVo Service (Sept. 3, 2008), available at http://commcns.org/Vrv9dM; Don Reisenger, DirecTV TiVo DVR Delayed to 2011, CNET News (Oct. 4, 2010 12:37 PM), http://commcns.org/Va0QuQ. 
Table 2. Concentration in the Navigation Devices Market

\begin{tabular}{cccc}
\hline & $\mathbf{2 0 0 8}$ & $\mathbf{2 0 0 9}$ & $\mathbf{2 0 1 0}$ \\
\cline { 2 - 4 } Revenue-based HHI & 5,667 & 2,020 & 1,913 \\
Unit-based HHI & 5,475 & 2,417 & 1,849 \\
\hline Source: Infonetics Research (2011). & & \\
\hline
\end{tabular}

Also, some cable operators are finding ways to deliver video without using a set-top box, utilizing software-based security and delivering content from the "cloud" to a variety of devices. ${ }^{245}$ Cablevision, for example, claims to have hundreds of thousands of customers using its network DVR service, which eliminates an operator-supplied DVR by moving the recording capability into the cloud. ${ }^{246}$ Similarly, Comcast's Xfinity app for iPad allows users to both change channels and to stream TV shows and movies from Comcast's OnDemand catalog directly to their iPad. ${ }^{247}$ The growing number of over-the-top Internet-video equipment, such as Roku, Boxee, Western Digital, Logitech, GoogleTV, and Apple TV, among others, may soon be a competitor of, rather than a complement to, traditional video services that require a set-top box. ${ }^{248}$ For example, one over-the-top video vendor states that thirty percent of its customers cancel cable service after using its service. ${ }^{249}$ So, while many MVPDs are using over-the-top video as a complement to their services and Internetbased video is not ideal for all types of content, over-the-top services may

245 See, e.g., Ryan Lawler, Why Time Warner Cable Is Cutting Its Own Cord, GiGaOM (Jan. 7, 2011, 8:17 AM), http://commcns.org/102cLqY; Steve Donohue, The Disappearing Set-Top, LIGHT READING CABLE (Apr. 26, 2011), http://commens.org/W9a2dG.

246 Is the Set-Top Box on its Way Out? Cable Executives Sound Off, FierceCABLE (Nov. 23, 2010), http://commcns.org/WiS2yh; Graeme McMillan, Cablevision Launches iPad App Offering 300 Channels of Live TV, TIME (Apr. 4, 2011), http://commens.org/UxfxEm.

247 Alan Henry, Comcast Updates Xfinity App for iPhone, Adds On-Demand Streaming, APPSCOUT (May 25, 2011, 7:56 PM), http://commcns.org/13Ixzrg; see also Kevin C. Tofel, Qualcomm's Wi-Fi Chip Could Turn Handhelds into a TV Set-Top Box, GigaOm (June 1, 2011, 11:15 AM), http://commcns.org/VrvT2t.

248 See Steve Smith, Over-the-Top! 488 Million Households to be OTT-Capable by 2016. VIDBLOG (June 3, 2011, 1:03 PM), http://commens.org/10hsSWD; James K. Wilcox, Samsung: Cable Without Set-Top Boxes Coming Via TV Apps?, ConsumerRePORTS.oro (Jan. 11, 2011, 10:33 AM), http://commcns.org/W9abhd; Ben Drawbaugh, Could This be the Year We Get to Ditch the Cable Box?, ENGADGET (Jan. 9, 2011, 4:28 PM), http://commens,org/U4a4Gi; Tirsina Radu, Millions Ditch Cable for Netflix and Antennas, TG DAILY (Apr. 11, 2011, 8:47 AM), http://commens.org/11CaWpP.

249 Ryan Lawler, 30\% of PlayOn Users Cut the Cord, GIGAOM (Oct. 15, 2010, 9:00 AM), http://commcns.org/1 1CaXKm; Jon Orlin, Comcast Reports Drop in Cable Subscribers; John Orlin, Blames Economy, TECHCRUNCH (Oct. 27, 2010), http://commens.org/YbNY8r. 
serve as a potential competitor to traditional video services for some customers. Since the traditional set-top box is a strong complement to cable service (i.e., the box has no independent value), to the extent that over-the-top video services add to the competition in the MVPD market, they likewise add to the competition in the set-top box market. ${ }^{250}$

In our interpretation of Section 629(e)(2), we do not require consumers to be direct participants in the equipment market, and for obvious reasons. While Section 629(a) does refer to "commercially availab[ility] . . . to consumers," Section 629(e)(2) makes no reference "to consumers," but addresses only competition generally. ${ }^{251}$ Such differences in statutory language cannot be ignored. There is no linkage of "fully competitive" to the particular requirements in Section 629(a), and there is no mention of consumers in 629(e)(2). ${ }^{252}$ Indeed, Congress expressed concern in Section 629(e)(3) that the provisions of Section 629(a) may impede competition, ${ }^{253}$ implying that the full implementation of 629(a) may be in conflict with the requirements of 629(e)(1) and (2).

Further, had Congress intended the "to consumers" element to apply in the sunset provision, it could have drafted the Act so that sunset was possible only after the full implementation of Section 629(a) as it did elsewhere in the Act. ${ }^{254}$ Consider, for example, the language in Section 401 of the Act governing regulatory forbearance. ${ }^{255}$ Congress specifically limited the FCC's ability to forbear from certain parts of Section 251 and Section 271 of the 1996 Act, mandating that forbearance was not permitted until those requirements had been "fully implemented." 256 Section 629(e), however, contains no mandate for full implementation. ${ }^{257}$ In fact, it would not be possible to do so given Section 629(e)(3), which implies that full implementation may impede competition. If the MVPD market is competitive and the equipment market is competitive, then regulation is probably more harmful than helpful, even if consumers are unable to purchase set-top equipment directly from manufacturers. The statute reflects that intuition.

\footnotetext{
250 For further discussion on the economics of complementarity of service and equipment, see George S. Ford, Thomas M. Koutsky \& Lawrence J. Spiwak, Consumers and Wireless Carterfone: An Economic Perspective, Phoenix Cent. Pol'y Bull No. 21, Sept. 2008, at 5-9, available at $\mathrm{http} / / / \mathrm{commcns.org/U4afkL}$.

25147 U.S.C. \$ 549(a), (e)(2).

25247 U.S.C. $\$ 549$ (e).

253 Id.

25447 U.S.C. $\$ 160$.

255 Id.

256 Id.

257 Compare 47 U.S.C. § 549(e) with 47 U.S.C. \$ 160.
} 


\section{Sunsetting 629 Would Both Promote Competition and the Public Interest}

The third leg of the sunset provisions requires that reduced regulation of the video marketplace "promote competition" and be in the "public interest." our view, satisfying these standards is not a problem. For example, innovation in the set-top box, if important to consumers, is one means by which firms can compete. Commoditizing the technology, or hindering the freedom to innovate, may alter the nature-and impede the intensity-of competition. The point was not lost on Congress. Section 629(c) permits the agency to waive the regulatory requirements of Section 629(a):

[U]pon an appropriate showing by a provider of multichannel video programming and other services offered over multichannel video programming systems, or an equipment provider, that such waiver is necessary to assist the development or introduction of a new or improved multichannel video programming or other service offered over multichannel video programming systems, technology, or products. ${ }^{259}$

Thus, Congress recognized that under certain conditions, setting aside the rules may be "necessary to assist the development or introduction of a new or improved [services and technologies]." ${ }^{260}$ Eliminating regulation that deters innovation clearly serves the public interest. ${ }^{261}$

Also, different delivery technologies may face different compliance costs with the regulation. If so, then relative prices may change, altering the competitive dynamic of the MVPD market. Moreover, Section 629(a) imposes a price regulation on all MVPDs (i.e., not just cable companies) with regard to the set-top box (i.e., no subsidies), ${ }^{262}$ and the impact of this price regulation may differ across firms and technology types, altering the competitive dynamic.

But there is more: As noted above, even the Commission has conceded that its implementation of 629 has been a costly disaster, forcing operators and consumers to shoulder more than one billion dollars in costs without any discernible benefits. ${ }^{263}$ The agency also acknowledged that its rules would lead to increases in the prices for equipment, burdening consumers with the agency's

25847 U.S.C. $\$ 549(\mathrm{e})$.

25947 U.S.C. $\$ 549$.

260 Id. $\$ 549(\mathrm{c})$.

261 See In re Evolution Broadband, LLC's Request For Waiver of Section 76.1204(a)(1) of the Commission's Rules; Implementation of Section 304 of the Telecommunications Act of 1996; Commercial Availability of Navigation Devices, Memorandum Opinion and Order, 24 F.C.C.R. 7890 (May 28, 2009); January Waiver Requests, supra note 35, at 220; June 2007 Waiver Requests, supra note 35, at 11780; Guam Cablevision Memorandum, supra note 35 , at 11747 .

26247 U.S.C. $\$ 549(\mathrm{a})$.

263 George S. Ford \& Lawrence J. Spiwak, Outliving Its Usefulness: A Law and Economics Argument for Sunset of Section 629, PHOENIX CENT. POL'y BULL. No. 29, June 2011, at 26, available at http:/commcns.org/VMFNN6. 
experimentation. ${ }^{264}$ Furthermore, in FCC rule waivers, the agency has explicitly observed that relief render "substantial public interest benefits by significantly reducing costs . ..."265 By extending the regulatory mandate to DBS providers, the cost of regulatory compliance rises.

If the FCC proceeds quickly to sunset Section 629, the public will also benefit sizably from the avoidance of stranded research, deployment, marketing, and other costs incurred to bring AllVid to fruition. ${ }^{266}$ Similarly, as few customers have adopted CableCard and manufacturers have largely ceased investing in the technology, ${ }^{267}$ a sunset of Section 629 today minimizes stranded costs and affects few, if any, consumers. Alternately, if the agency makes another go at Section 629, it forces MVPDs to incur significant costs and also encourages manufacturers and customers to make financial commitments to the Commission's chosen standards. All of these commitments are technology-specific, and wasted if the agency's scheme falters, which it is bound to do given the economics of the issue and the dynamic nature of the video industry at present. ${ }^{268}$ Yet, if manufacturers and consumers expect failure, then, based on the historical evidence, both may proceed cautiously with their commitments to CableCARD and AllVid. If so, then the expected benefits of the regulatory scheme will be reduced, but the implementation costs by the MVPD industry will not, since MVPDs must incur such costs for their own equipment and on behalf of their customers. ${ }^{269}$ Such hedging makes for an unfavorable costbenefit analysis for Section 629.

Last, and certainly not least, putting an end to the Section 629 debacle is entirely consistent with the stated purpose of the 1996 Act, "to reduce regulation," ${ }^{270}$ and President Obama's recent Executive Order that called upon federal agencies to conduct a cost-benefit review of existing federal regulation $\mathrm{s}^{27}$ in order to eliminate those that are "excessive, inconsistent, and redundant."272

264 See AllVid NOI, supra note 2, at 4275, 4301 (statement of Comm'r Baker); see also Commercial Availability III, supra note 3, I 14 ("[W] recognize that mandating this approach could be costly for some cable operators."); NATIONAL BROADBAND PLAN, supra note 3 , at 50-51.

265 AllVid NOI, supra note 2, $\{9$.

266 Ford \& Spiwak, Outliving Its Usefulness, supra note 263, at 26.

267 Id. at 26-27.

268 NATIONAL BROADBAND Plan, supra note 3, at 50-52.

269 Ford \& Spiwak, Outliving Its Usefulness, supra note 263, at 27.

270 Telecommunications Act of 1996, Pub. L. No. 104-104, pmbl., 110 Stat 56, 56 (codified at 47 U.S.C. $\$ 609$ ).

271 Exec. Order No. 13,563, 76 Fed. Reg. 3821, 3822 (Jan. 18, 2011 ) (applying Order to "agencies" as defined in Exec. Order No. 12,866); Exec. Order No. 12,866, 3 C.F.R. 1925 (Sept. 30, 1993) (defining "agency" as those defined under 44 U.S.C. $\$ 3502(1)$ ). But see 44 U.S.C. $\$ 3502(5)$ (including the FCC as within the definition of an "independent regulatory agency," thus outside the scope of Exec. Order 13,563).

272 Barack Obama, Toward a 21st-Century Regulatory System, WALL ST. J. (Jan. 18, 
While the FCC, as an "independent" agency, is exempt from complying with this directive, Chairman Julius Genachowski has wholeheartedly endorsed both the letter and the spirit of the President's directive. ${ }^{273}$ Surely, if ever there was a candidate to show that the Commission was truly committed to removing outmoded regulations, then ending the Commission's tortured fourteen-year experiment with Section 629 is a prime contender.

\section{CONCLUSION}

Where one stands depends on where one sits. We argue in this paper that the FCC needs to alter its perception on the proper implementation of Section 629 with this reorientation based on the economics of the multichannel video market and the role of the set-top box. Specifically, we argue that the common view that the set-top box is a tool by which multichannel video providers can extract surplus from consumers is invalid. Multichannel video providers, including cable companies, have no anticompetitive motivation with regard to the set-top box. In fact, multichannel video providers prefer the efficient outcome, and the interest of the MVPD and the consumer is common-cheaper, more innovative set-top boxes increase consumer valuations of multichannel video services and, in turn, increase profits. If a commercial market for such equipment is relatively more efficient than self-supply, then the multichannel video provider will embrace it, thus, increasing its profit while also increasing consumer welfare. Alternately, if self-supply is more efficient, then the multichannel video provider prefers self-supply - also to the benefit of consumers. The multichannel video provider has strong incentives to reduce the price and cost of converter equipment as well as to pursue value-enhancing innovation. Therefore, if we observe self-supply of set-top equipment, then the presumption should be that self-supply is relatively more efficient than a commercial market. It follows, then, that a regulation-forced commercial market for such devices is likely to produce higher prices and lower economic and consumer welfare.

We acknowledge that the Commission may sense some legal obligation to address the mandates of Section 629 . That said, the agency retains the flexibility to either minimize or maximize its intrusion into the video marketplace. We argue that the FCC should consider, at least for a moment, that the dominance of self-supply in the set-top box market is a consequence of its relative effi-

2011), http://commens.org/SQH8TY; see also Elizabeth Williamson, Obama Launches Rule Review, Pledging to Spur Jobs, Growth, WALL ST. J. (Jan. 18, 2011), http://commens.org/11CbjRo.

273 Julius Genachowski, Chairman, Fed. Commc'n Comm'n, Address at the Broadband Acceleration Conference, at 4 (Feb. 9, 2011), available at http://commens.org/SQHoST. 
ciency. Economic logic provides some support for this view, thereby encouraging a more temperate implementation strategy, which means something unlike the heavy-handed AllVid approach. The additional fact that the video market is evolving at a rapid pace further supports a sober approach to Section 629. ${ }^{274}$ Regulations designed and implemented today will be archaic in the very near term. ${ }^{275}$

Like it or not, until the underlying economic reality changes, the FCC's anticipated aggressive approach to Section 629 is likely-as FCC Commissioner Robert McDowell notes-to keep the agency in "the Valley of Unattained Goals." ${ }^{276}$ For this reason, we have presented in this paper plausible legal, economic, and evidentiary arguments on how the Commission can justify the sunset of Section 629 , thereby purging from the policy debate the view that billions should be wasted on a futile task simply "because Congress told us to."277 While we understand that the Commission has extended significant political capital in raising the AllVid issue both in the National Broadband Plan and in a subsequent Notice of Inquiry, initiating a formal Notice of Proposed Rulemaking will set the agency on a course that, once started, will be difficult to reverse and could result in another CableCARD-like failure. Present market conditions in the multichannel video market, while not perfectly competitive in the textbook sense, are such that regulatory efforts are unlikely to create more benefits than costs. As a result, Section 629 has "outlived its usefulness" and should be put to bed.

274 AllVid NOI, supra note 2, ๆ 13 (stating that "delivery platforms continue to evolve at a rapid pace").

275 See, e.g., Commercial Availability Fourth NPRM, supra note 141, at 4328 (statement of Comm'r McDowell, stating that "technological innovation continues to outpace the government's ability to keep up").

${ }^{276}$ Commercial Availability III, supra note 3, at 14,711 (statement of Comm'r McDowell).

277 Id. 